\title{
A STUDY ON EFFECT OF WATER TANKS MODELED AS TUNED MASS DAMPERS ON DYNAMIC PROPERTIES OF STRUCTURES
}

\author{
D. Rupesh Kumar ${ }^{1}$, Fahimeh Hoseinzadeh ${ }^{2}$ \\ ${ }^{1}$ Assistant Professor, Department of Civil Engineering, University College of Engineering (A), Osmania University, \\ Hyderabad-500007, T.S., India; PH (+91)-4027097125; (+91)-9985542205 \\ ${ }^{2}$ M.E. Scholar, Department of Civil Engineering, University College of Engineering (A), Osmania University, \\ Hyderabad-500007, T.S., India; PH (+91)-4027097125
}

\begin{abstract}
Here a suitable TMD system (water tank as a lumped mass without sloshing effect) is modeled on top/intermediate storey of building. The Response Spectrum method is considered as per IS 1893-Part1-2002. Seven RCC framed buildings are considered; rectangular buildings with vertical irregularity of 10,14 and 20 storey with height to depth ratio (H/D) as $0.875,1.23$ and 1.6 respectively; and 14 storey $L$-shaped building with $H / D$ as 1.23; rectangular buildings with vertical regularity of 10,14 and 20 storey with H/D as 3.9, 5.44 and 8 respectively. The TMDs are modeled, with 3\% total weight of each floor, using eight different cases. In total 63 building models are analyzed with/without TMDs by ETABS software and the results are presented. It is found that for extracting the maximum benefits, the buildings shall be modeled with three TMDs using 3-Gauss points at the intermediate storey as it reduces all the three parameters viz. time period, base shear and storey drift simultaneously to the maximum possible extent; and the reduction in the base shear is significant for buildings with smaller H/D as well as with higher H/D too. The TMD models are found to improve the performance of buildings under earthquake loads.
\end{abstract}

Keywords: Tuned mass damper, water tank, earthquake load, time period, base shear, storey drift, height to depth ratio, Gauss points, ETABS software.

\section{INTRODUCTION}

Vibration control of environmentally induced motions in civil engineering structures has been a topic of intensive research over the last 30 years. A need for new and better means of designing new structures and retrofitting existing ones from the damaging effects of severe dynamic loadings has motivated civil engineer to embark on rather unfamiliar but innovative concepts of structural control. The use of lightweight, high strength materials, and advanced construction techniques have led to increasingly flexible and lightly damped structures, which is prone to cause human discomfort, structural damage and even failure in extreme dynamic loadings. The means to suppress undesirable levels of vibration have then become essential and integral aspect of structural system in tall buildings.

The passive mass dampers have endured longer and rigorous validation, and have reached the stage of full implementation. In fact passive mass dampers, e.g., tuned mass dampers (TMDs), tuned liquid dampers (TLDs) and tuned liquid column dampers (TLCDs) have been implemented with some degree of success.

TMD is attached to a structure in order to reduce the dynamic response of the structure. The frequency of the damper is tuned to a particular structural frequency so that when that frequency is excited, the damper will resonate out of phase with the structural motion. The mass is usually attached to the building via a spring -dashpot system and energy is dissipated by the dashpot as relative motion develops between the mass and the structure.
1.1 Types of Passive Control Devices and Control

\section{Methods}

The different passive control devices are: metallic yield dampers, friction dampers, viscoelastic dampers, viscous fluid dampers, tuned liquid damper, and tuned mass dampers. The different control methods are: active control, passive control, hybrid control, and semi-active control.

\subsection{Existing Towers}

The first installation of TMD on a structure was the Centrepoint Tower in Sydney, Australia. There are two buildings in the United States equipped with TMDs; one is the John Hancock Tower in Boston and the other is the Citicorp Centre in New York City. The Citicorp Centre building is $279 \mathrm{~m}$ high with a damping ratio of $1 \%$ along each axis. The Citicorp TMD is located on the sixty-third floor in the crown of the structure. The damper is expected to reduce the building sway amplitude by about $50 \%$. Two dampers were added to the 60-storey John Hancock Tower in Boston to reduce the response to wind loading. The dampers are placed at opposite ends of the fifty-eighth storey, $67 \mathrm{~m}$ apart, and move to counteract sway as well as twisting due to the shape of the building.

\section{REVIEW OF LITERATURE}

The TMD concept was first applied by Frahm in 1909 to reduce the rolling motion of ships as well as ship hull vibrations. A theory for the TMD was presented later in the paper by Ormondroyd and Den Hartog (1928) followed by a 
detailed discussion of optimal tuning and damping parameters in Den Hartog,,s book on mechanical vibrations (1947). The initial theory was applicable for an undamped single degree of freedom (SDOF) system subjected to a sinusoidal force excitation. Extension of the theory to damped SDOF systems has been investigated by numerous researchers.

Clark Allen (1988) proposed a methodology for designing multiple TMDs for reducing building response motion. The technique was based on extending Den Hartog ${ }^{\text {ee }}$ s work from a SDOF to multiple degrees of freedom (MDOF). Simplified linear mathematical models were excited by $1940 \mathrm{El}$ Centro earthquake and significant motion reduction was achieved using the design technique.

Kwok and Samali (1995) discussed the performance of TMDs under wind loads. The performance of both passive and active TMD systems can be readily assessed by parametric studies which have been the subject of numerous researches. Few experimental verifications of TMD theory have been carried out, particularly those involving active control, but the results of those experiments generally compared well with those obtained by parametric studies. Despite some serious design constraints, a number of passive and active TMD systems have been successfully installed in tall buildings and other structures to reduce the dynamic response due to wind and earthquake.

Shimazu and Araki (1996) dealt with a survey of actual effectiveness of mass damper systems installed in buildings. In this paper the real state of the implementation of mass damper systems, the effects of these systems were clarified based on various recorded values in actual buildings against both wind and earthquake. The effects were discussed in relation with the natural period of buildings equipped with mass damper systems, the mass weight ratios to building weight, wind force levels and earthquake ground motion levels.

Housner et al (1996) discussed about the past, present, and future of structural control. The paper basically provided a concise point of departure for those researchers and practitioners who wishing to assess the current state of the art in the control and monitoring of civil engineering structures; and provided a link between structural control and other fields of control theory, pointing out both differences and similarities, and points out where future research and application efforts are likely to prove fruitful. Samali and Al-Dawod (2003) explained the performance of a five -storey benchmark model using an active TMD (ATMD) and a fuzzy logic controller (FLC). The simulation analysis of the five -storey benchmark building for the uncontrolled building, the building with TMD, and the building with ATMD with Fuzzy and linear quadratic regulator (LQR) controllers has been reported, and comparison between Fuzzy and LQR controllers was made. In addition, the simulation analysis of the benchmark building with different values of frequency ratio, using a Fuzzy controller was conducted and the effect of mass ratio has been studied.
Ghosh and Basu (2004) dealt with the effect of soil interaction on the performance of TMDs for seismic applications. The properties of the structure used in the design of the TMD were those evaluated considering the structure to be of a fixed-base type. These properties of the structure may be significantly altered when the structure has a flexible base. In such cases, it was necessary to study the effects of soil-structure interaction (SSI) while designing the TMD for the desired vibration control of the structure. The behavior of flexible-base structures with attached TMD, subjected to earthquake excitations has been investigated. Modified structural properties due to SSI have been covered.

Chien-Liang Lee et al (2006) presented optimal design theories and applications of TMDs. Full states of the dynamic system of MDOF structures, multiple TMDs (MTMDs) installed at different storey of the building, and the power spectral density (PSD) function of environmental disturbances were taken into account. The optimal design parameters of TMDs in terms of the damping coefficients and spring constants corresponding to each TMD were determined through minimizing a performance index of structural responses defined in the frequency domain. Moreover, a numerical method was also proposed for searching for the optimal design parameters of MTMDs in a systematic fashion such that the numerical solutions converge monotonically and effectively toward the exact solutions as the number of iterations increases. The feasibility of the proposed optimal design theory was verified by using a SDOF structure with a single TMD (STMD), a five-DOF structure with two TMDs, and a tenDOF structure with a STMD.

Saidi et al (2011) proposed development of passive viscoelastic damper to attenuate excessive floor vibrations. Recent changes in the construction of building floors have included the use of light material composite systems and long span floor systems. Although these changes have many advantages, such floor systems can suffer from excessive vibration due to human activities. This problem is exacerbated in office buildings due to the reduction in inherent damping associated with modern fit outs. Excessive floor vibrations are often realized after the completion of construction or following structural modifications and normally arise due to inadequate knowledge of the damping values in the design process. Thus rectification measures are normally required to reduce floor accelerations. This paper proposed a new innovative passive viscoelastic damper to reduce floor vibrations. This damper can be easily tuned to the fundamental frequency of the floor and can be designed to achieve various damping values. The paper discusses the analytical development of the damper with experimental results presented on a prototype to demonstrate its effectiveness.

Wong (2008) dealt with seismic energy dissipation of inelastic structures with TMDs. The energy transfer process of using a TMD in improving the ability of inelastic structures to dissipate earthquake input energy was 
investigated. Inelastic structural behavior was modeled by using the force analogy method, which was the backbone of analytically characterizing the plastic energy dissipation in the structure. The effectiveness of TMD in reducing energy responses was also studied by using plastic energy spectra for various structural yielding levels. Results show that the use of TMD enhances the ability of the structures to store larger amounts of energy inside the TMD that will be released at a later time in the form of damping energy when the response was not at a critical state, thereby increasing the damping energy dissipation while reducing the plastic energy dissipation. This reduction of plastic energy dissipation relates directly to the reduction of damage in the structure, and TMD is therefore concluded to be quite effective in protecting structures from suffering major damage during an earthquake.

Guo and Chen (2008) presented dynamic analysis of space structures with MTMDs. Formulations of the reverberation matrix method (RMM) are presented for the dynamic analysis of space structures with MTMDs. The theory of generalized inverse matrices was then employed to obtain the frequency response of structures with and without damping, enabling a uniform treatment at any frequency, including the resonant frequency. For transient responses, the Neumann series expansion technique as suggested in RMM was found to be confined to the prediction of accurate response at an early time. The artificial damping technique was employed here to evaluate the medium and long time response of structures. The free vibration, frequency response, and transient response of structures with MTMD were investigated by the proposed method through several examples. Numerical results indicated that the use of MTMD can effectively alter the distribution of natural frequencies as well as reduce the frequency/transient responses of the structure. The high accuracy, lower computational cost, and uniformity of formulation of RMM were also highlighted.

Alexander and Schilder (2009) discussed about exploring the performance of a nonlinear TMD (NTMD). In this paper the performance of an NTMD, which was modeled as a two degree of freedom (DOF) system with a cubic nonlinearity had been covered. This nonlinearity was physically derived from a geometric configuration of two pairs of springs. The springs in one pair rotate as they extend, which results in a hardening spring stiffness. The other pair provided a linear stiffness term. In this paper an extensive numerical study of periodic responses of the NTMD using the numerical continuation software AUTO has been done. Two techniques has been employed for searching the optimal design parameters; optimization of periodic solutions and parameter sweeps. Here the authors have discovered a family of resonance curves for vanishing linear spring stiffness.

Maryam Bitaraf et al (2010) presented application of semiactive control strategies for seismic protection of buildings with magneto-rheological (MR) dampers. MR dampers are semi-active devices that can be used to control the response of civil structures during seismic loads. They are capable of offering the adaptability of active devices and stability and reliability of passive devices. One of the challenges in the application of the MR dampers is to develop an effective controlstrategy that can fully exploit the capabilities of the MR dampers. This study proposed two semi -active control methods for seismic protection of structures using MR dampers. The first method was the simple adaptive control method which is classified as a direct adaptive control method. The controller developed using this method can deal with the changes that occur in the characteristics of the structure because it can modify its parameters during the control procedure. The second controller was developed using a genetic -based fuzzy control method. In particular, a FLC whose rule base determined by a multi-objective genetic algorithm was designed to determine the command voltage of MR dampers.

Chi-Chang Lin et al (2010) discussed about vibration control of seismic structures using semi-active friction multiple TMDs (SAF-MTMD). An energy dissipation mechanism is an indispensable part of a TMD system, since it reduces the mass stroke of a system to a manageable level. Dry friction is a natural source of energy dissipation for TMDs. Nevertheless, there is no difference between a friction-type TMD and a dead mass added to the primary structure if static friction force inactivates the mass damper. To overcome this disadvantage, this paper proposed a novel SAF-MTMD for vibration control of seismic structures. Using variable friction mechanisms, the proposed SAFMTMD system is able to keep all of its mass units activated in an earthquake with arbitrary intensity. A comparison with a system using passive friction-type multiple TMDs (PFMTMDs) demonstrates that the SAF-MTMD effectively suppresses the seismic motion of a structural system, while substantially reducing the strokes of each mass unit, especially for a larger intensity earthquake. This means that applying the SAF-MTMD requires less installation space than a PF-MTMD system. The current study also shows that the SAF-MTMD performs well in a low-intensity earthquake, in which the PF-MTMD is inactivated due to friction.

Welt and Modi (1989) presented experimental study on the effectiveness of TLDs under wave loading. Byung-Wan Jo et al (2001) discussed about structural vibration of TMDinstalled three-span steel box bridge. Runlin Yang et al (2002) explained about seismic structural control using semi-active TMDs. Constantinou and Symans (1992) presented experimental and analytical investigation of seismic response of structures with supplemental fluid viscous dampers. Ahsan and Yukio (1994) dealt with damping systems for controlling wind induced motions of structures. Blekherman (1996) enlightened about mitigation of response of high-rise structural systems by means of optimal TMD. Chen and Wu (2001) outlined optimal placement of multiple TMDs for seismic structures. Nawawi Chouw (2004) dealt with behavior of soil -structure system with TMDs during near-source earthquakes. Mehdi Setareh et al (2007) conferred about semi-active TMD for floor vibration control. 
Many authors dealt with various options for reducing the dynamic load response parameters viz. time period, base shear and storey drift for different structures. But, to the authors ${ }^{\text {ee }}$ knowledge, no researcher has conducted studies on effectiveness of adding a dead mass (water tank as lumped mass without sloshing effect) to the primary structure as a suitable TMD system. Hence, the same investigations are done in the present numerical studies.

\section{MATHEMATICAL FORMULATIONS}

\subsection{Concept of TMD using Two Mass System}

The equation of motion for primary mass as shown in Figure 1 is

$$
(1+\overline{\mathrm{m}}) \ddot{\mathrm{u}}+2 \xi \omega \mathrm{m} \dot{\mathrm{u}}+\omega^{2} \mathrm{u}=\frac{p}{m}-\overline{\mathrm{m}} \ddot{\mathrm{u}}_{\mathrm{d}}
$$

$\overline{\mathrm{m}}$ is defined as the mass ratio, $\mathrm{m}=\mathrm{m}_{\mathrm{d}}^{\prime} \mathrm{m}$

$$
\omega^{2}=\frac{\mathrm{k}}{\mathrm{m}}, \mathrm{C}=2 \xi \omega \mathrm{m}, \mathrm{C}_{\mathrm{d}}=2 \xi \omega_{\mathrm{d}} \mathrm{m}_{\mathrm{d}}
$$

Where, $\dot{\mathrm{u}}$ is the velocity ; $\ddot{\mathrm{u}}$ is the acceleration $; \xi$ is the damping factor of the primary mass. The equation of motion for tuned mass is given by

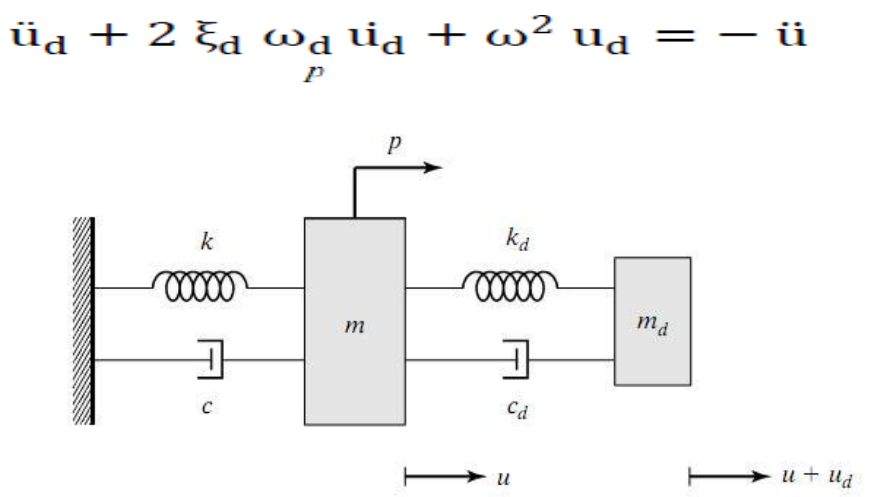

Fig 1 SDOF-TMD system

\subsection{TMD Theory for SDOF Systems}

\subsubsection{Undamped Structures: Undamped TMD}

$$
\begin{gathered}
\mathrm{m}_{\mathrm{d}}\left(\ddot{\mathrm{u}}_{\mathrm{d}}+\ddot{\mathrm{u}}\right)+\mathrm{k}_{\mathrm{d}} \mathrm{u}_{\mathrm{d}}=-\mathrm{m}_{\mathrm{d}} \mathrm{a}_{\mathrm{g}} \\
\mathrm{m} \ddot{\mathrm{u}}+\mathrm{k} \mathrm{u}_{\wedge}-\mathrm{k}_{\mathrm{d}} \mathrm{u}_{\mathrm{d}}=-\mathrm{m}_{\mathrm{g}}+\mathrm{p} \\
\mathrm{a}_{\mathrm{g}}=\mathrm{a}_{\mathrm{g}} \sin \Omega \mathrm{t}, \mathrm{p}=\mathrm{p} \sin \Omega \mathrm{t}
\end{gathered}
$$

Then the response is given by

$$
\tilde{u}=u^{\wedge} \sin \Omega t, u_{d}=u_{d}^{n} \sin \Omega t
$$

\subsubsection{Undamped Structures - Damped TMD}

$$
\begin{gathered}
m_{d} \ddot{u}_{d}+c_{d} \dot{u}_{d}+k_{d} u_{d}+m_{d} \ddot{u}=-m_{d} a_{g} \\
m \ddot{u}+k u-c_{d} \dot{u}_{d}-k_{d} u_{d}=-m a_{g}+p
\end{gathered}
$$

\section{NUMERICAL STUDIES}

In the present numerical studies high rise buildings are modeled using ETABS package. The Response Spectrum method is considered as per IS 1893-Part1-2002 (seismic zone 5-very severe; type of soil-medium). The framed structures are analyzed using dynamic analysis and the time period, magnitudes of displacements at critical locations are recorded. There after suitable TMD systems are designed and applied. The weight of the TMD is $3 \%$ to $5 \%$ of the total weight of the one floor. The bear structure is analyzed and designed to arrive at the suitable sectional dimensions of the members. After that TMDs are modeled using eight cases.

Case 1: One TMD modeled at the center of gravity of the top storey

Case 2: Four TMDs modeled at four corners at the top storey

Case 3: One TMD modeled at the mid height

Case 4: One TMD modeled at the second storey

Case 5: Four TMDs modeled each at quarter, half, three quarter and full heights

Case 6: Two TMDs modeled one at the top and other at the mid height

Case 7: Two TMDs modeled using 2-Gauss points at the intermediate storey

Case 8: Three TMDs modeled using 3-Gauss points at the intermediate storey

In the present studies, seven RCC framed buildings are analyzed. These include two categories of buildings, namely, buildings with vertical irregularity and buildings with vertical regularity. The buildings with vertical irregularity consist of four buildings.

B1: 10 storey rectangular building with height to depth ratio (H/D) as 0.875 B2: 14 storey rectangular building with H/D as 1.23

B3: 20 storey rectangular building with H/D as $1.6 \mathrm{~B} 4: 14$ storey L-shaped building with H/D as 1.23

The buildings with vertical regularity consist of three buildings. B5: 10 storey rectangular building with H/D as 3.9

B6: 14 storey rectangular building with $\mathrm{H} / \mathrm{D}$ as $5.44 \mathrm{~B} 7: 20$ storey rectangular building with $\mathrm{H} / \mathrm{D}$ as 8

They are analyzed using dynamic analysis and the time period, displacements and the base shear was compared with the results obtained from the model without TMD to illustrate the utility of the studies.

The TMD is evolved based on the concept of creating ancillary structure on the primary structure such that the frequency of the ancillary structure is as close as possible to the primary structure so as to achieve the fundamental frequency of the primary structure. Hence, $3 \%$ of mass ratio is used in the present studies.

$$
\omega_{1}=\sqrt{(K / m)}
$$


The frequency of ancillary structure, which is a SDOF system, shall have the same frequency as that of the primary structure. The methods of dynamic analysis are: Response spectrum analysis, pushover analysis, inelastic time history analysis.

\subsection{Plans of Buildings and Calculations}

Here, the plan, elevation, 3D models and numerical calculations of the seven buildings that are studied by modeling TMDs using different cases are shown in the following sections. The plan and 3D model of all buildings are illustrated in Figure 2 through Figure 8.

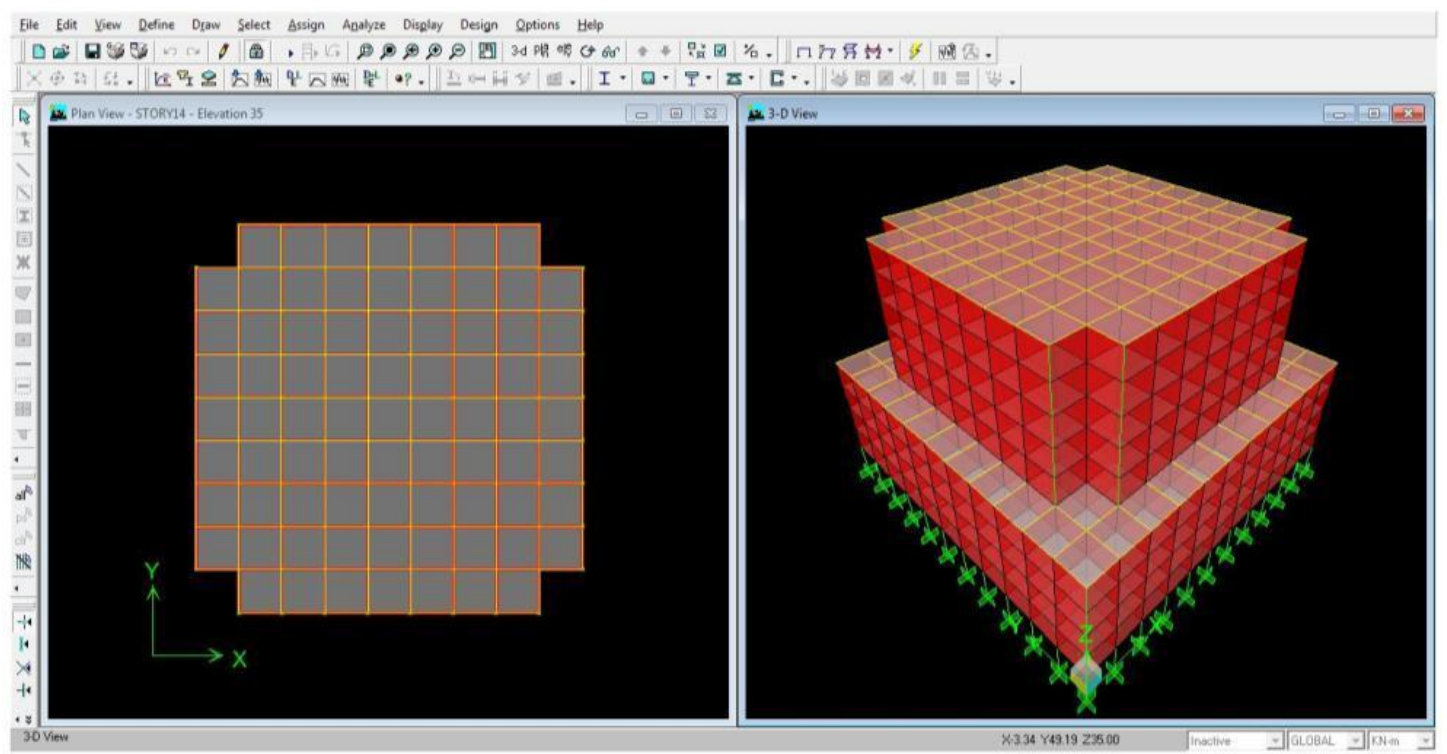

Fig 210 storey rectangular building with H/D as 0.875 (B1)

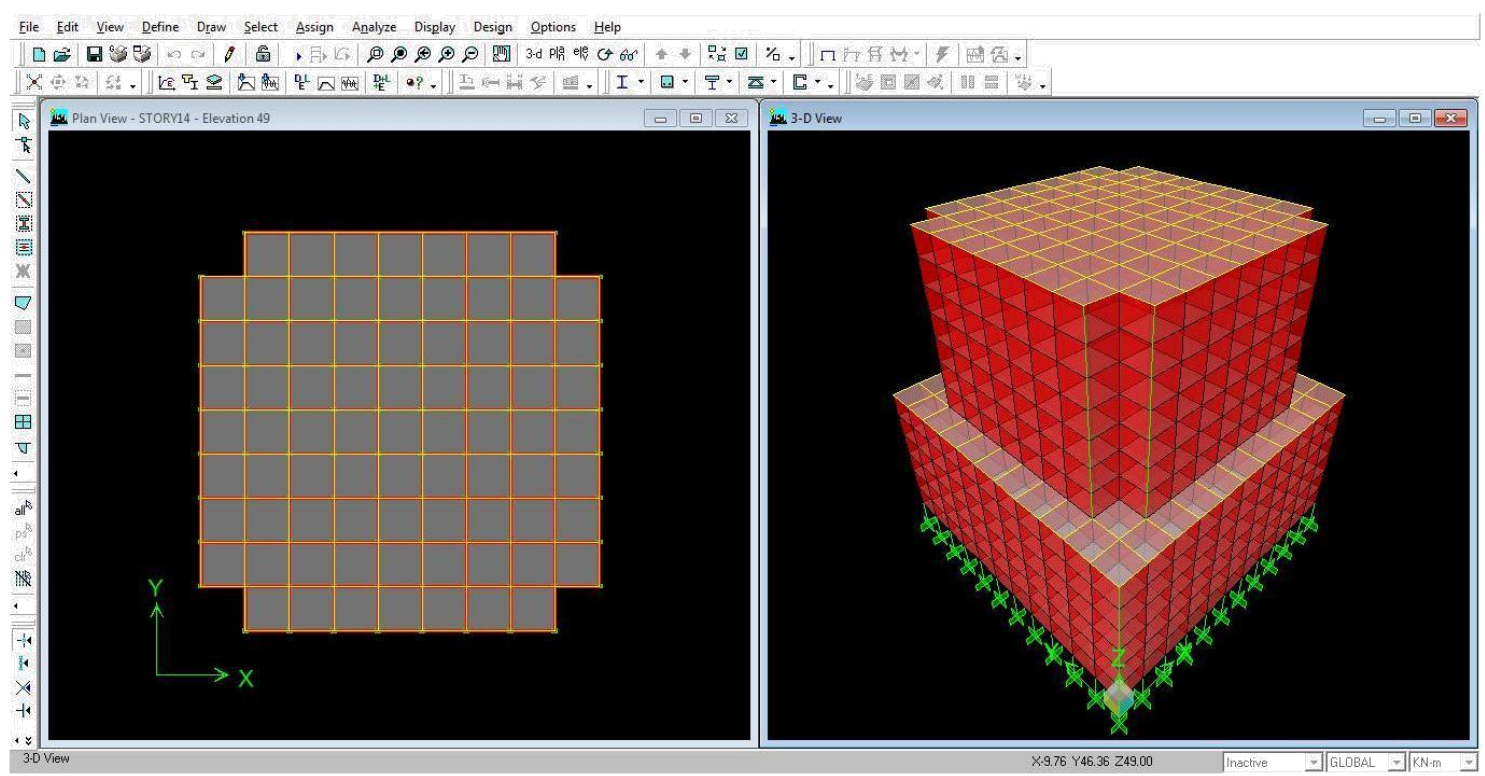

Fig 314 storey rectangular building with H/D as 1.23 (B2) 


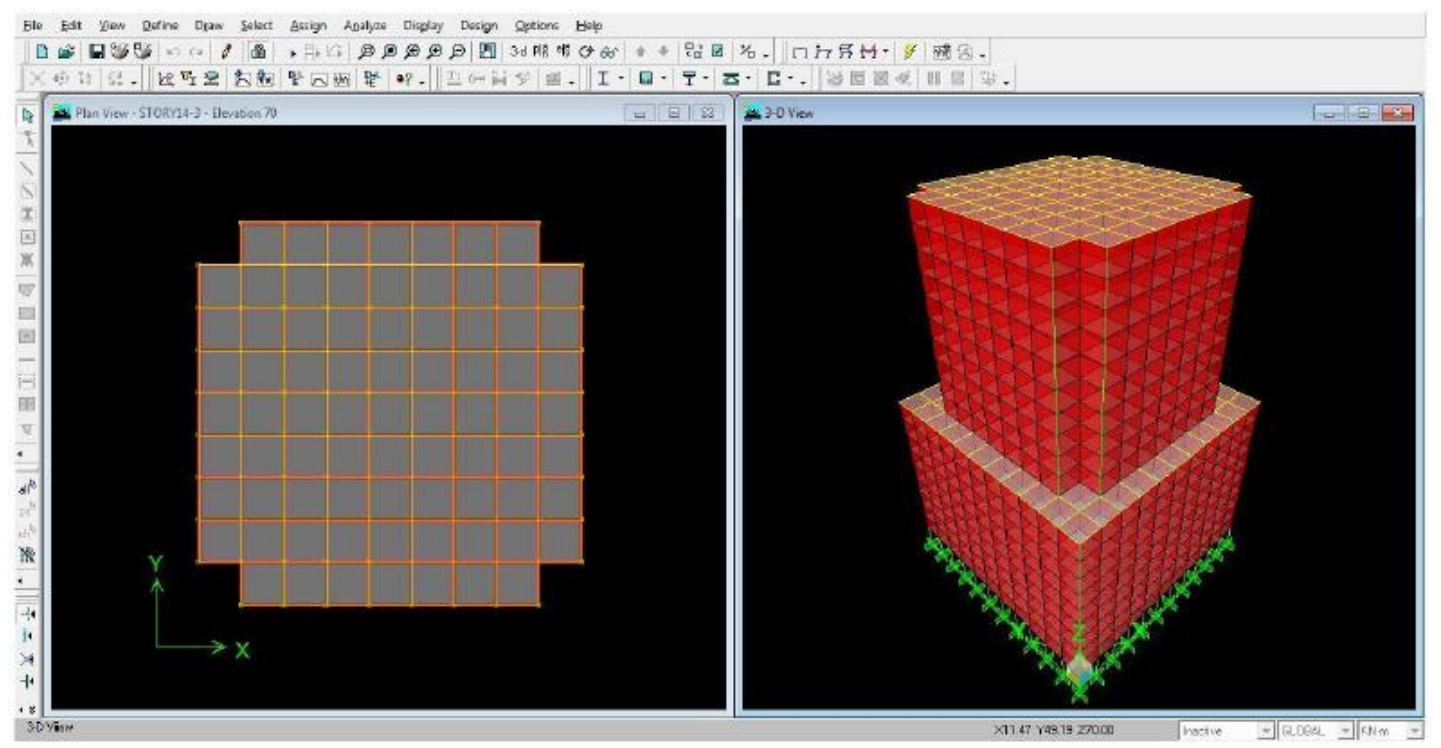

Fig 420 storey rectangular building with H/D as 1.6 (B3)

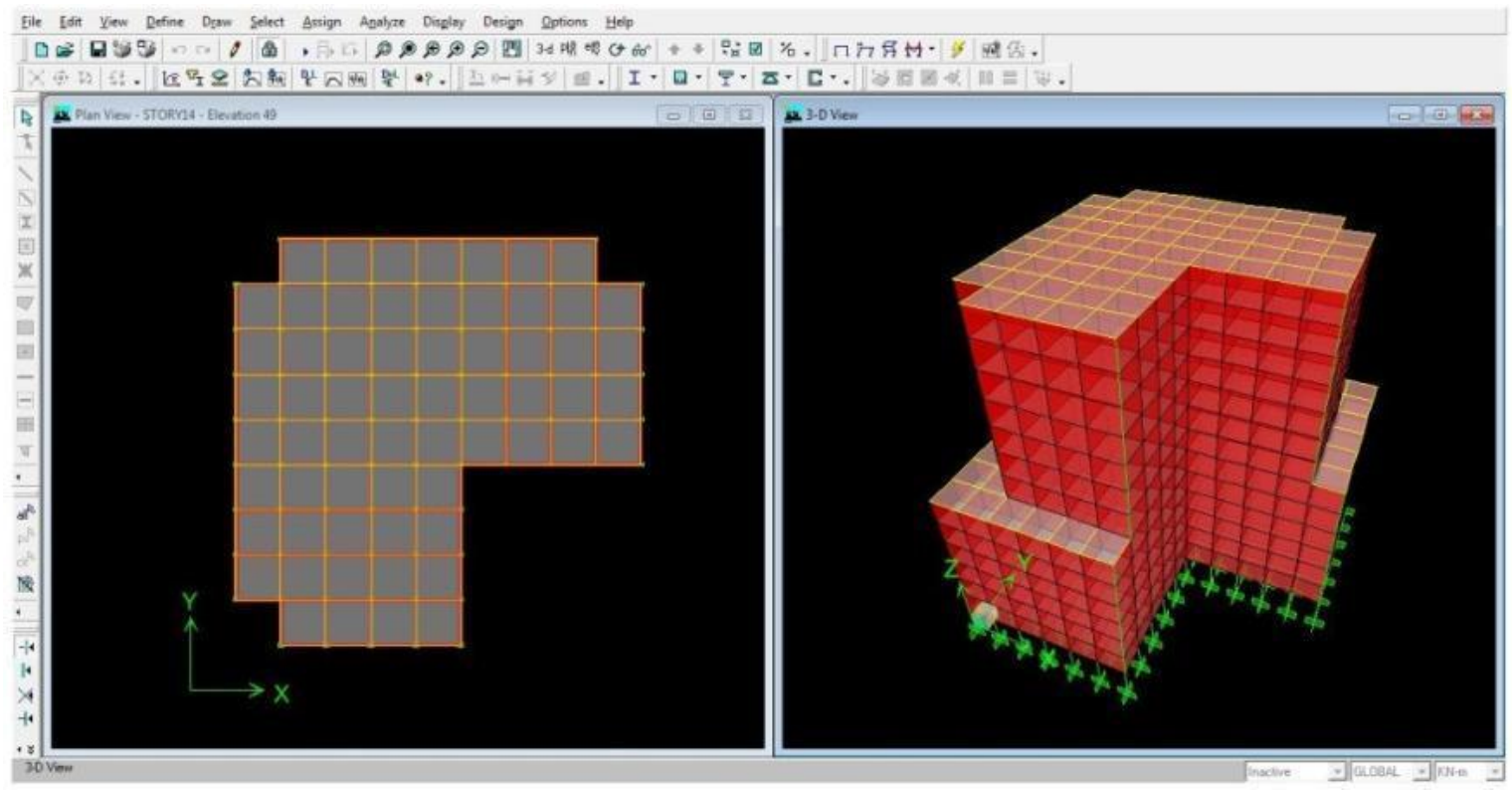

Fig 514 storey L-shaped building with H/D as 1.23 (B4)

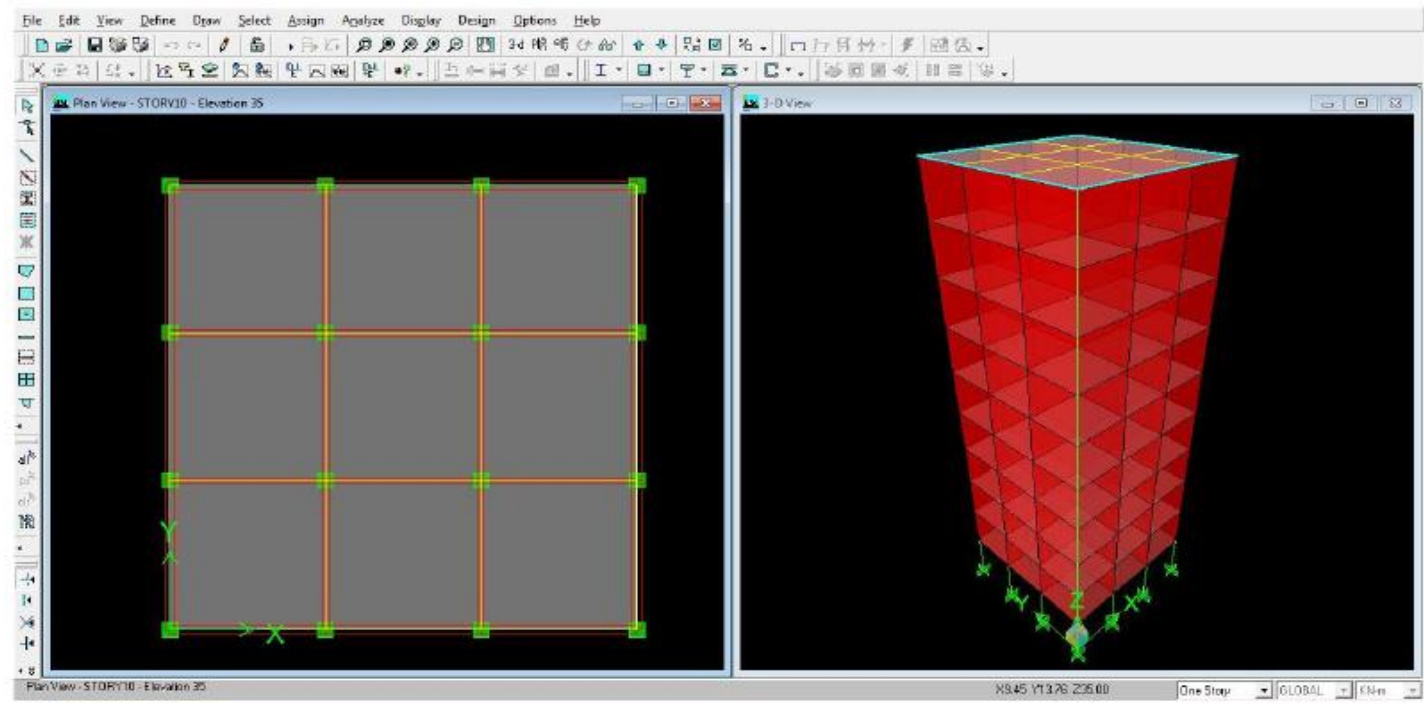

Fig 610 storey rectangular building with H/D as 3.9 (B5) 


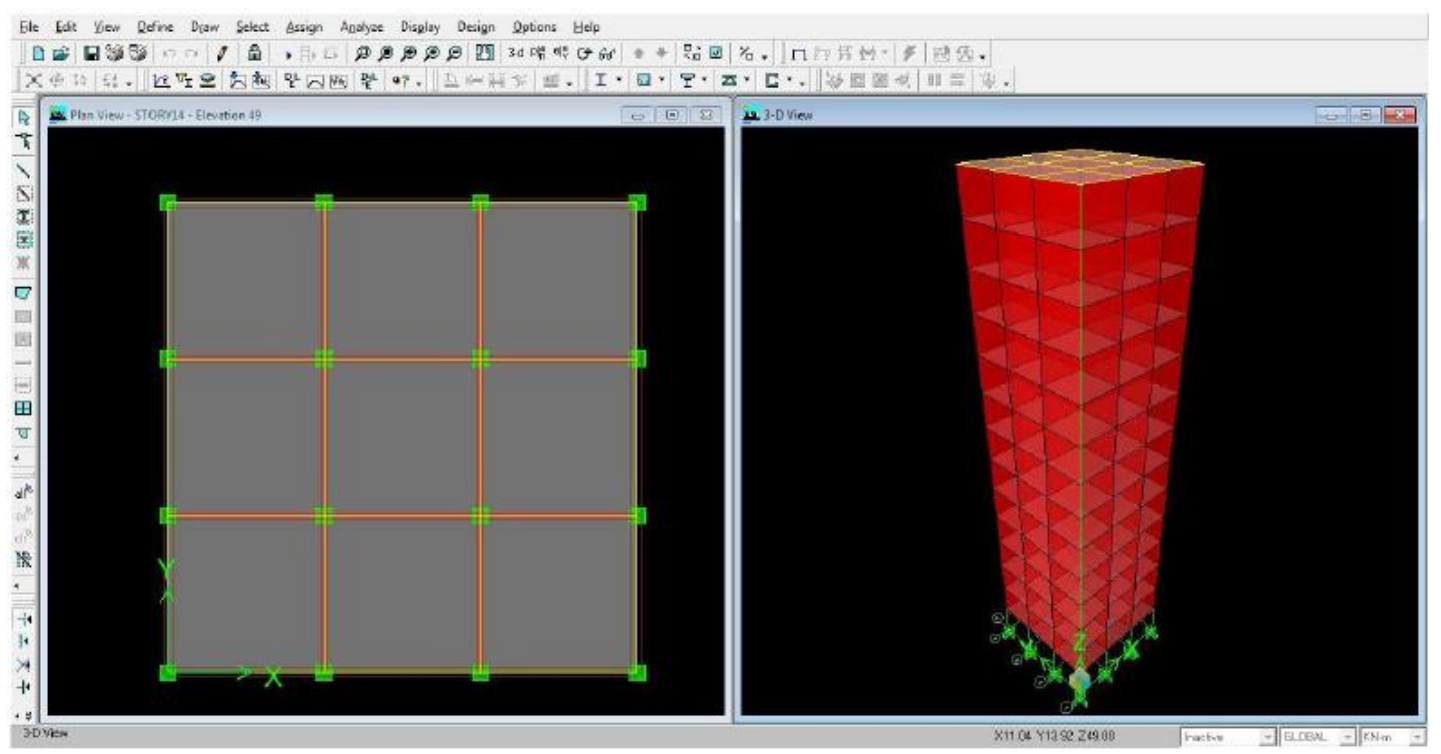

Fig 714 storey rectangular building with H/D as 5.44 (B6)

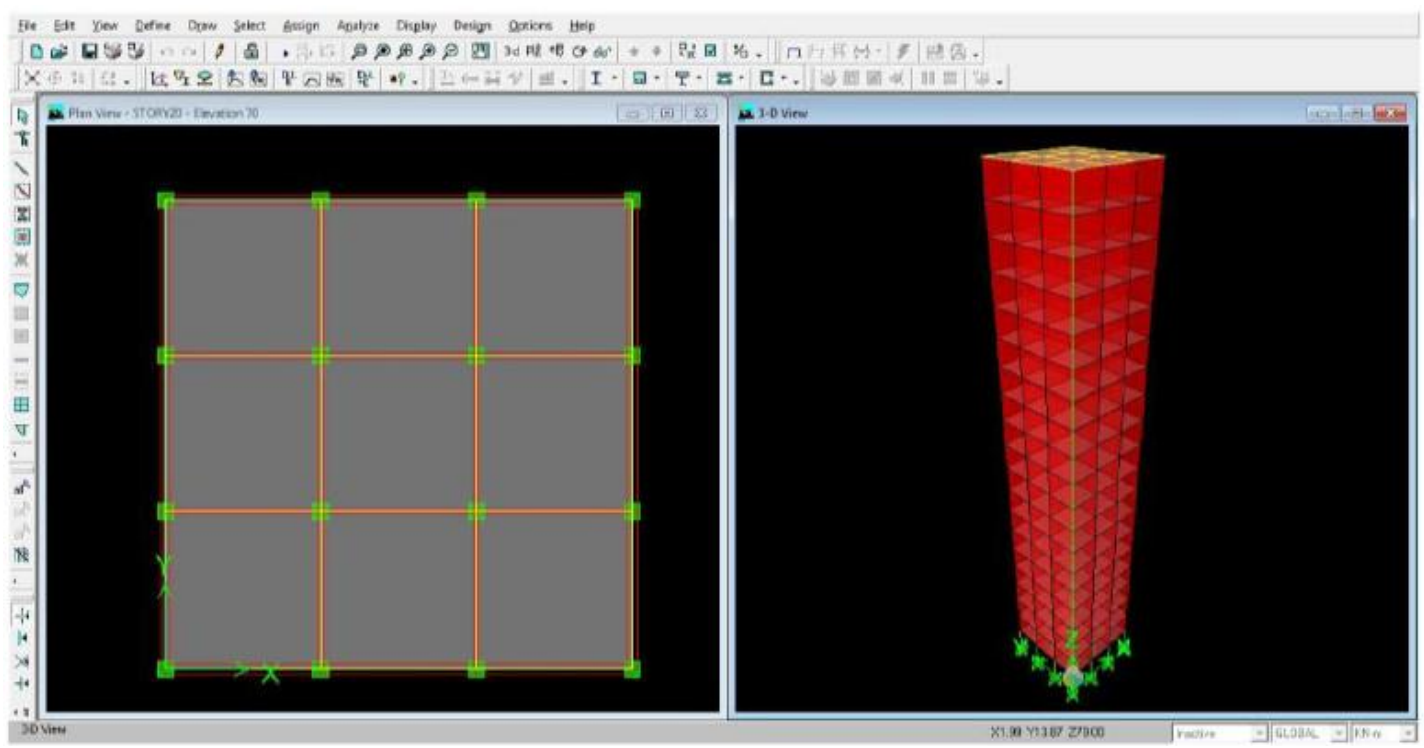

Fig 820 storey rectangular building with H/D as 8 (B7)

Calculations for 20 storey building with plan and vertical irregularity with H/D ratio as 1.6 is given in next section in detail. And calculations for all other buildings are tabulated in Table 1. The TMDs are modeled on each of the building for all eight cases. The elevation and 3D model of the 20 storey rectangular RCC framed building with vertical and plan irregularity and H/D ratio as 1.6 for eight cases of modeling TMDs are illustrated in Figure 9 through Figure 16.

\subsection{Calculations for Single TMD - One Water Tank}

Size of beam $=0.25 \mathrm{~m} \times 0.4 \mathrm{~m}$

Size of column $=0.9 \mathrm{~m} \times 0.9 \mathrm{~m}$

$\mathrm{S}_{\text {thich }}=0.15 \mathrm{~m}$

$\mathrm{W}_{\text {out }}=0.25 \mathrm{~m}$

$\mathrm{W}_{\text {in }}=0.15 \mathrm{~m}$

Concrete $=$ M 20 grade, Steel $=\mathrm{Fe} 415$ grade

Specific weight of $\mathrm{RCC}=25 \mathrm{kN} / \mathrm{m}^{3}$
Specific weight of brick $=20 \mathrm{kN} / \mathrm{m}^{3}$ Imposed load $=3 \mathrm{kN} / \mathrm{m}^{2}$ on all floors Young ${ }^{\text {ee }}$ modulus of concrete $=5000$

Number of storey $=20$

Height of storey $=3.5 \mathrm{~m}$

Number of water tanks $=1$

Response spectra = IS 1893-Part1-2002

Seismic zone $=5$ (Table 2, IS 1893-Part1-2002)

Type of soil $=$ Medium

\subsection{Stiffness Calculation}

Moment of inertia of columns $=(1 / 12) \times 0.9 \times 0.9^{3}=54.675$ x $10^{-3} \mathrm{~m}^{4}$

Stiffness of each column $=\mathrm{K}=12 \mathrm{EI} / \mathrm{L}^{3}=12 \times 22360 \times 10^{3}$ x $54.675 \times 10^{-3} / 3.5^{3}=342166.67 \mathrm{kN} / \mathrm{m}$ 
Total stiffness $=$ Number of columns $\mathrm{x}$ stiffness of each column $=5474666.73 \mathrm{kN} / \mathrm{m}$ Stiffness of columns of water $\operatorname{tank}=(3 / 100) \times 5474666.73=164240 \mathrm{kN} / \mathrm{m}$ Stiffness of each column of water tank $=(1 / 4) \times 164240.0019=41060$ $\mathrm{kN} / \mathrm{m}$

\subsection{Calculation of Depth of Column of Water Tank}

Let $d_{1}, b_{1}$ be the depth and width of water tank.

Stiffness of each column of water tank $=12 \mathrm{EI} / \mathrm{L}^{3}=41060$

$\mathrm{kN} / \mathrm{m}$

$\mathrm{I}_{1}=6.561 \times 10^{-3} \mathrm{~m}^{4}$

Assuming width of column of water tank (b1) $=0.4 \mathrm{~m}$

$\mathrm{I}_{1}=\mathrm{b}_{1} \mathrm{~d}_{1}{ }^{3} / 12=6.561 \times 10^{-3} \mathrm{~m}^{4}$
Then $\mathrm{d}_{1}=0.58 \mathrm{~m}$

Size of each column of water tank $=0.4 \mathrm{~m} \times 0.58 \mathrm{~m}$

\subsection{Calculation of Total Weight at Each Floor}

Total weight of each floor $=$ weight of $($ slab + beams + columns + outer walls + inner walls +imposed loads $)=$ $38474 \mathrm{kN}$

Weight of one water tank with columns $=(3 / 100) \times 38474=$ $1154.22 \mathrm{kN}$ Weight of four columns of water tank $=4 \times 0.4$ x $0.75 \times 3.5 \times 25=105 \mathrm{kN}$

Weight of water tank $=1154.22-105=1049.22 \mathrm{kN}$ Water tank dimensions $=4 \mathrm{~m} \mathrm{x} 4 \mathrm{~m} \mathrm{x} 4 \mathrm{~m}$

Table 1 Stiffness and loads on all buildings

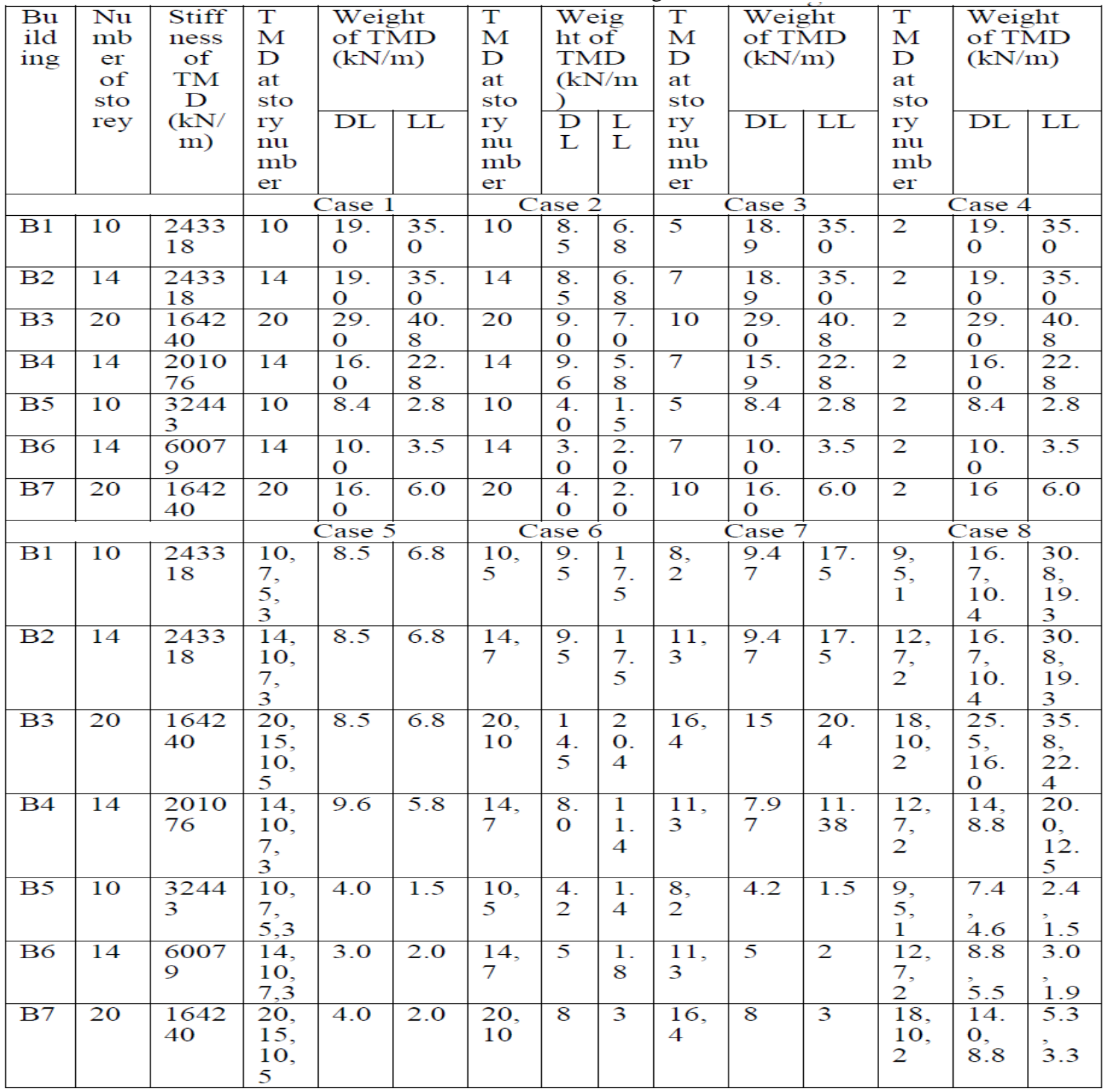




\section{Top Slab}

$\mathrm{DL}=0.1 \times 4 \times 4 \times 25+0.02 \times 4 \times 420=47 \mathrm{kN}$

$\mathrm{LL}=0.75 \times 4 \times 4=12 \mathrm{kN}$

\section{Bottom Slab}

$\mathrm{DL}=0.15 \times 4 \times 4 \times 25+0.05 \times 4 \times 4 \times 20=76 \mathrm{kN}$

$\mathrm{LL}=$ Weight of water tank $=4 \times 4 \times 4 \times 10=640 \mathrm{kN}$
$\mathrm{DL}=0.2 \times 4 \times 4 \times 25=80 \mathrm{kN}$ for one wall $\mathrm{DL}=80 \mathrm{kN} \times 4$ $=180 \mathrm{kN}$

Total DL $=47+76+320=446 \mathrm{kN}$ Total $\mathrm{LL}=12+640=$ $652 \mathrm{kN}$ Total load $=1098 \mathrm{kN}$

Total DL on each beam $=446 / 4=111.5 \mathrm{KN}$ or $111.5 / 4=$ $29 \mathrm{kN} / \mathrm{m}$ Total LL on each beam $=652 / 4=163 \mathrm{KN}$ or 143 $/ 4=40.75 \mathrm{kN}$

\section{Side Walls}

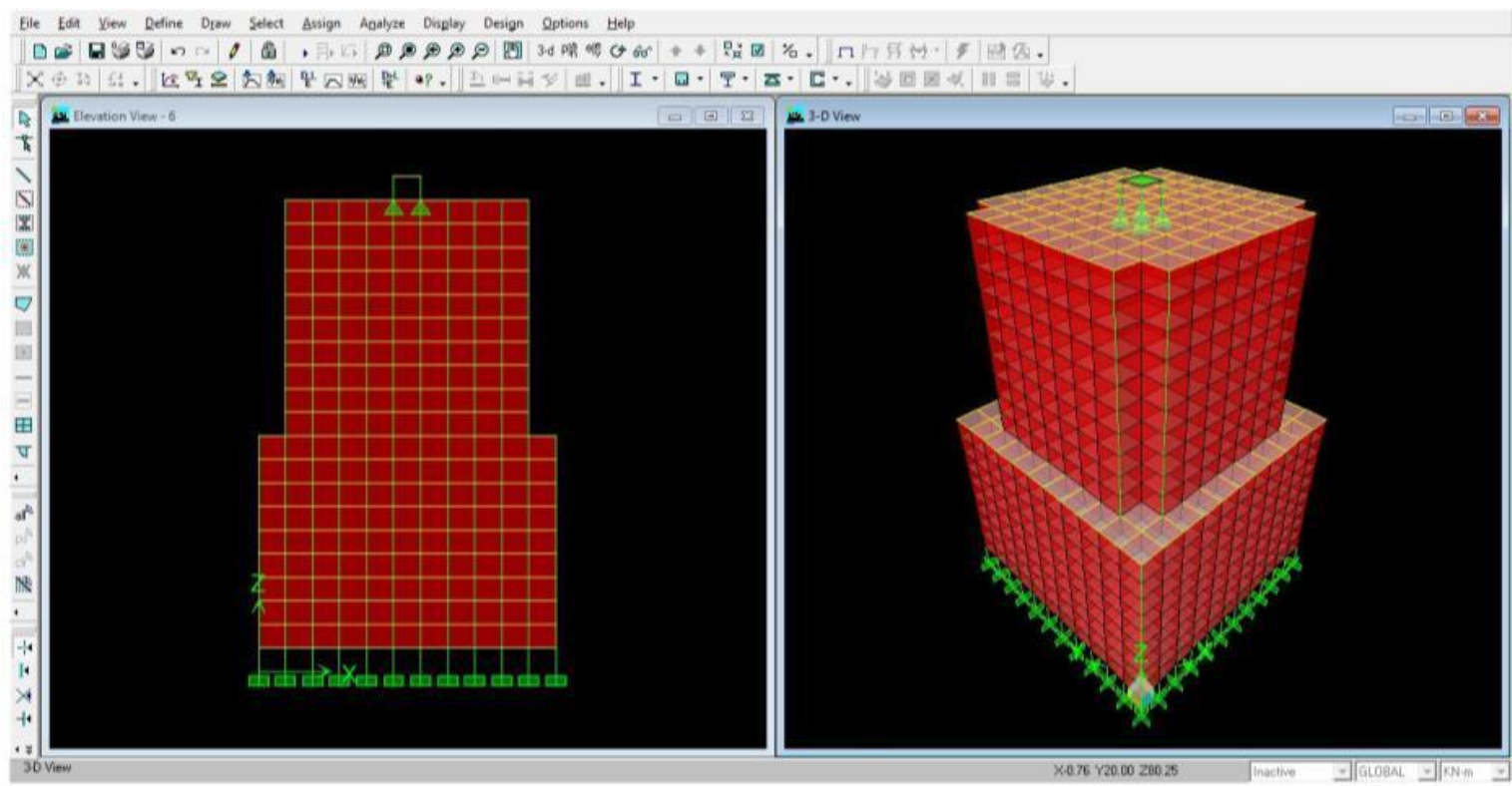

Fig 920 storey rectangular building with one TMD at CG of top storey (Case 1)

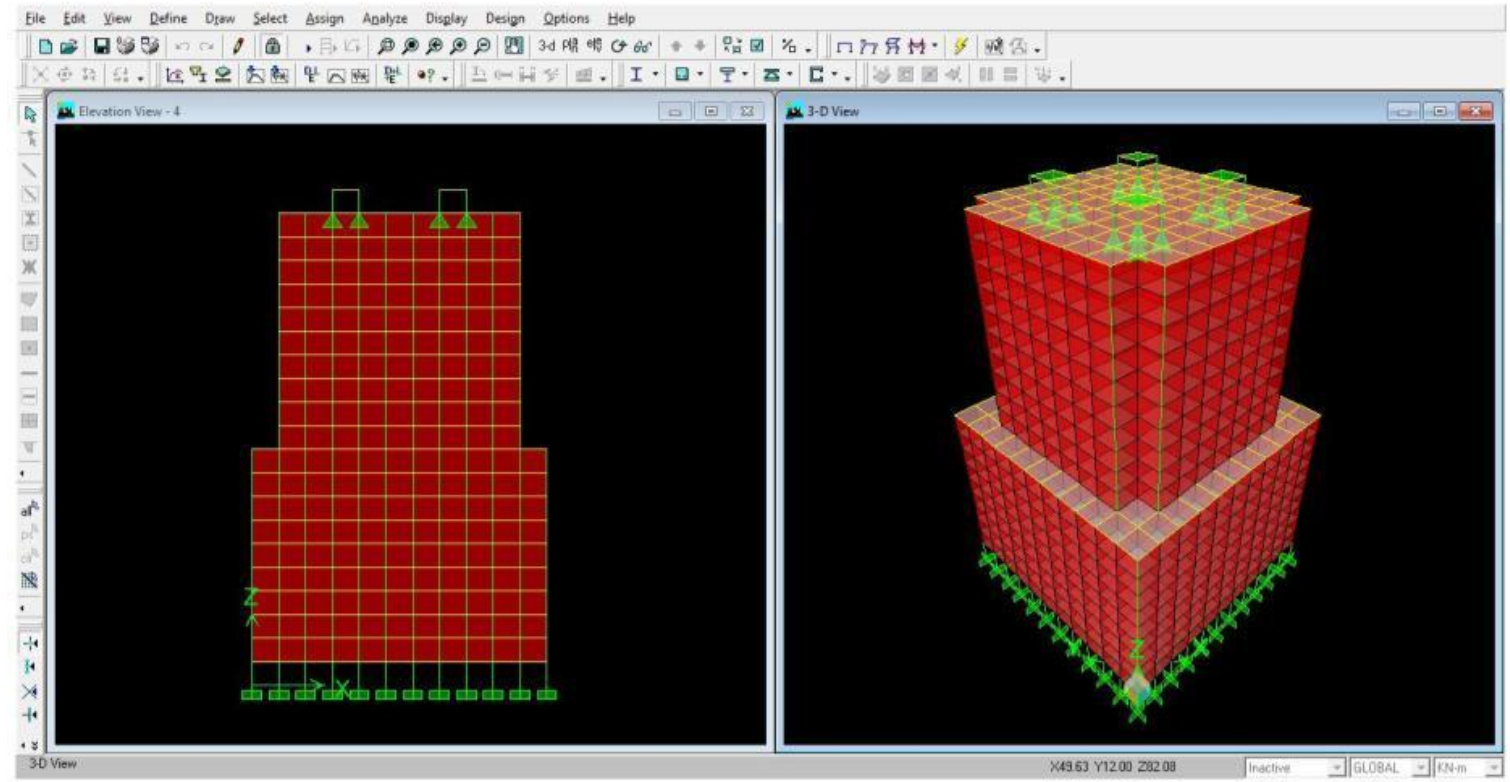

Fig 1020 storey rectangular building with four TMDs at four corners at top storey (Case 2) 


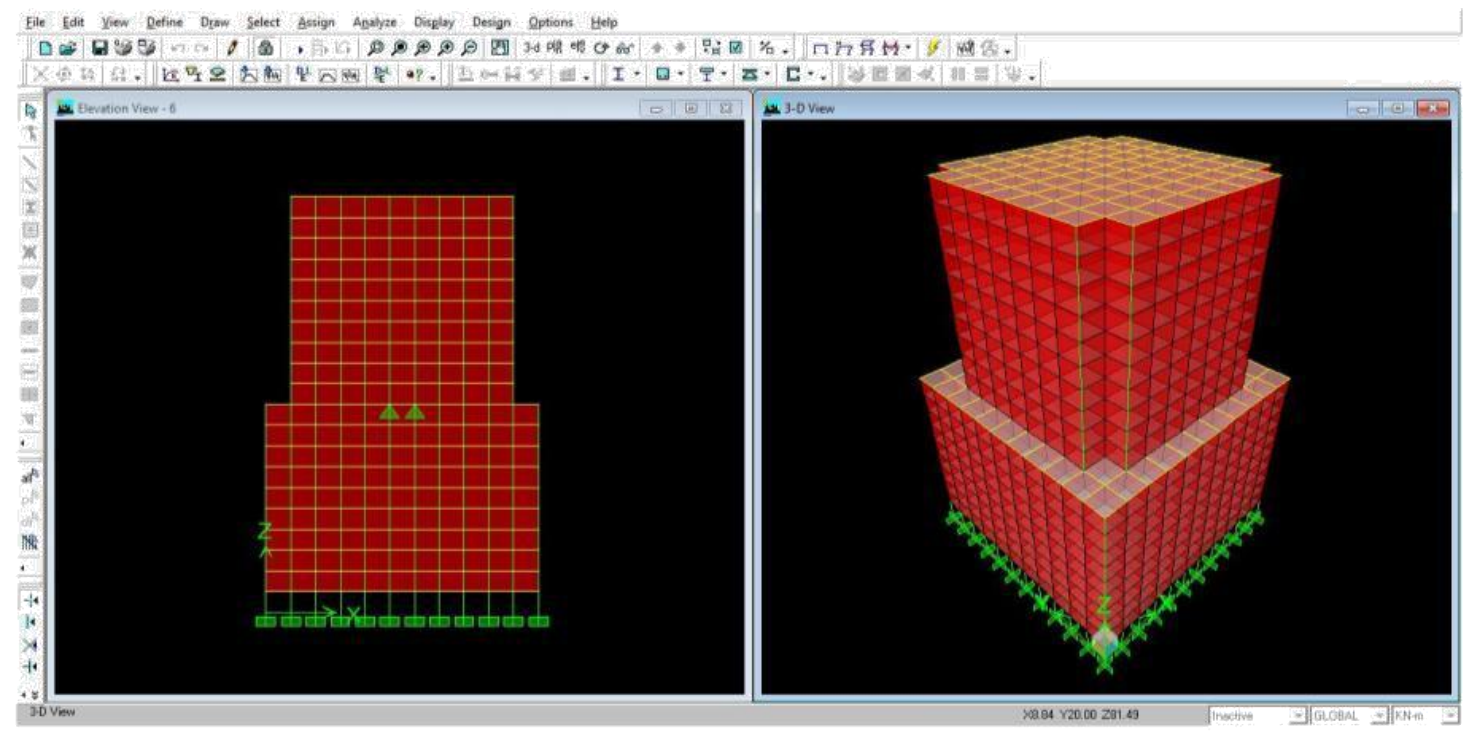

Fig 1120 storey rectangular building with one TMD at mid height (Case 3)

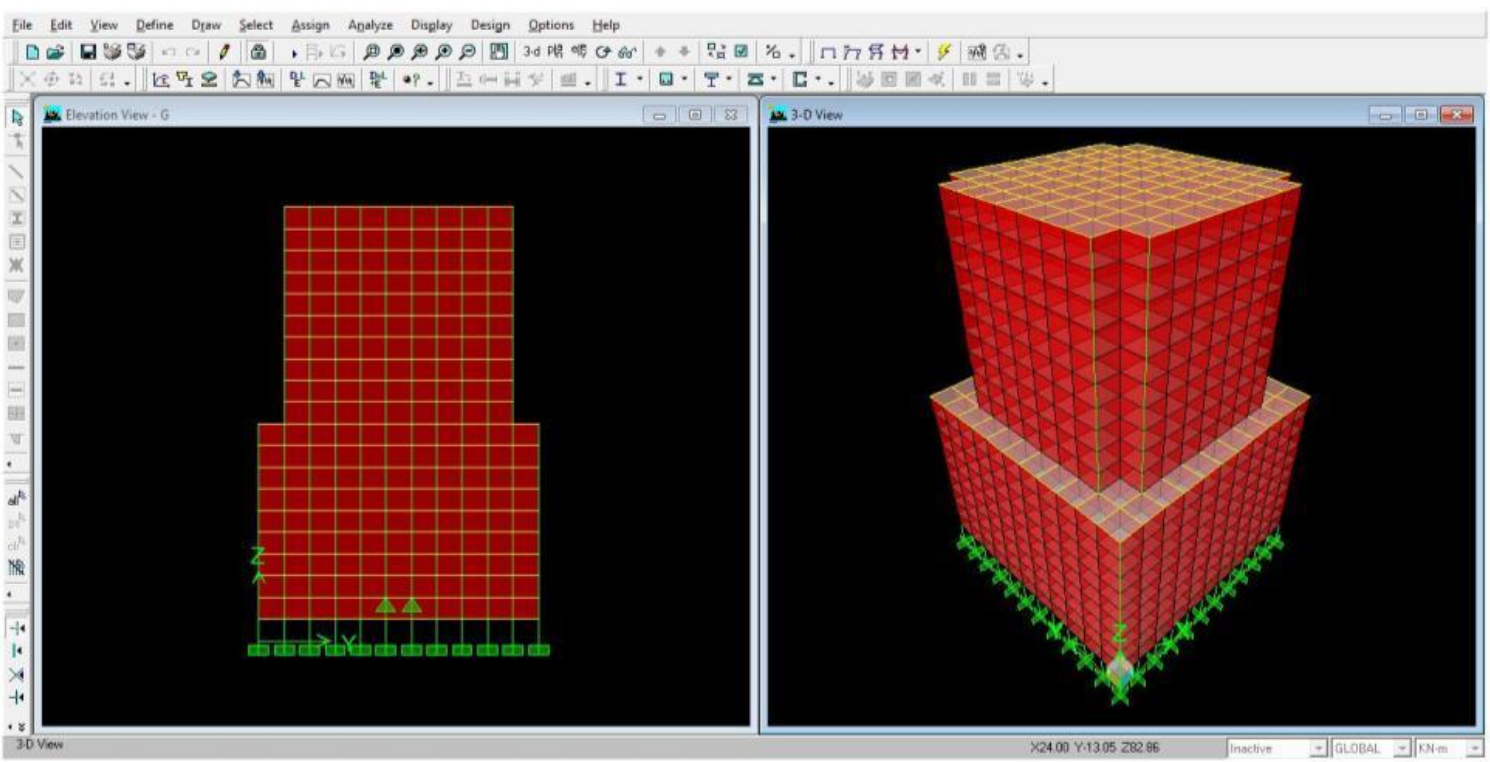

Fig 1220 storey rectangular building with one TMD at second storey (Case 4)

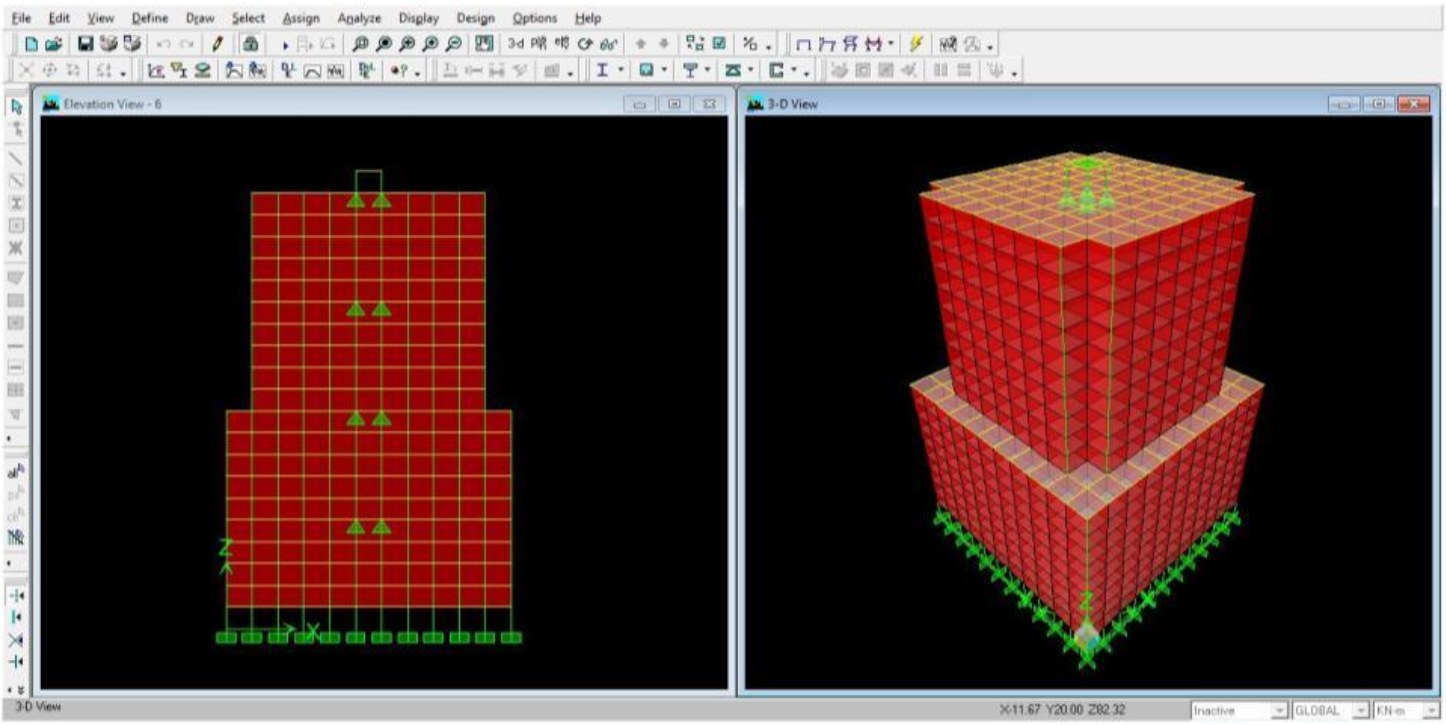

Fig 1320 storey rectangular building with four TMDs at quarter, half, three-quarter and full heights (Case 5) 


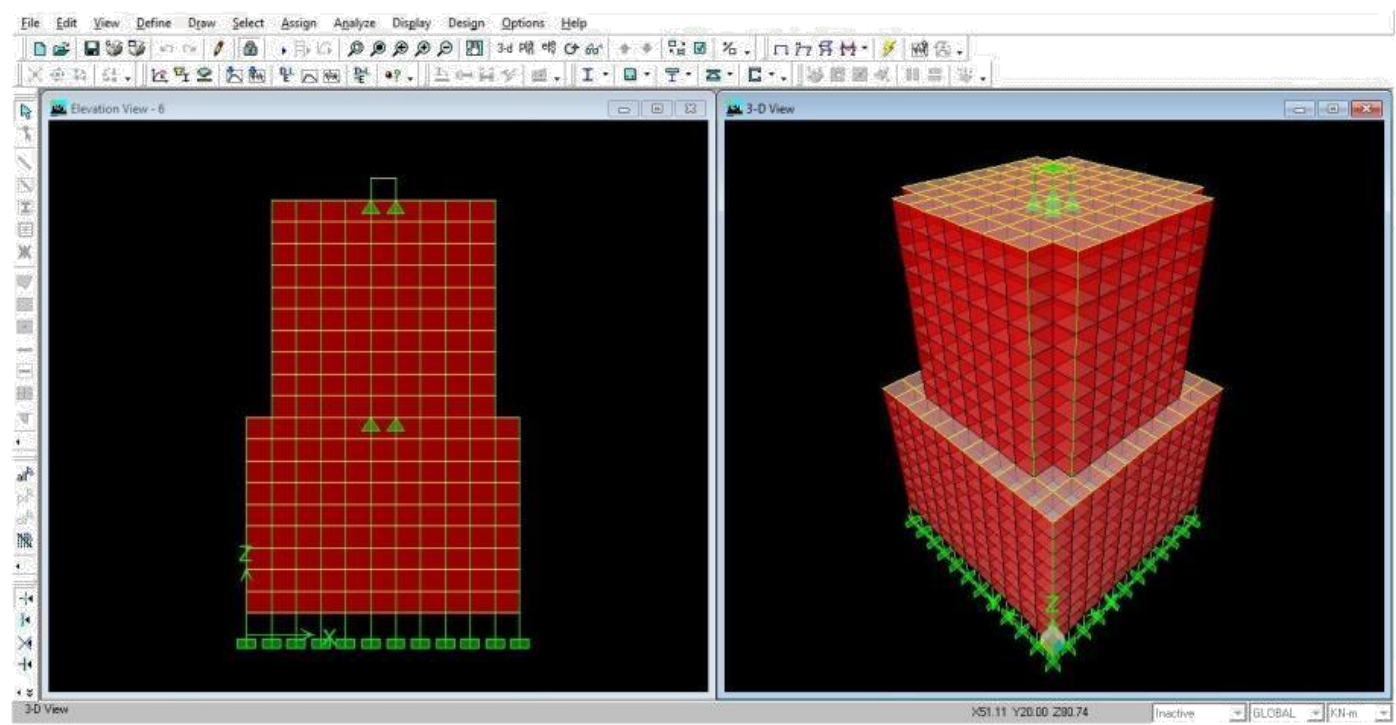

Fig 1420 storey rectangular building with two TMDs one at top and other at mid height (Case 6)

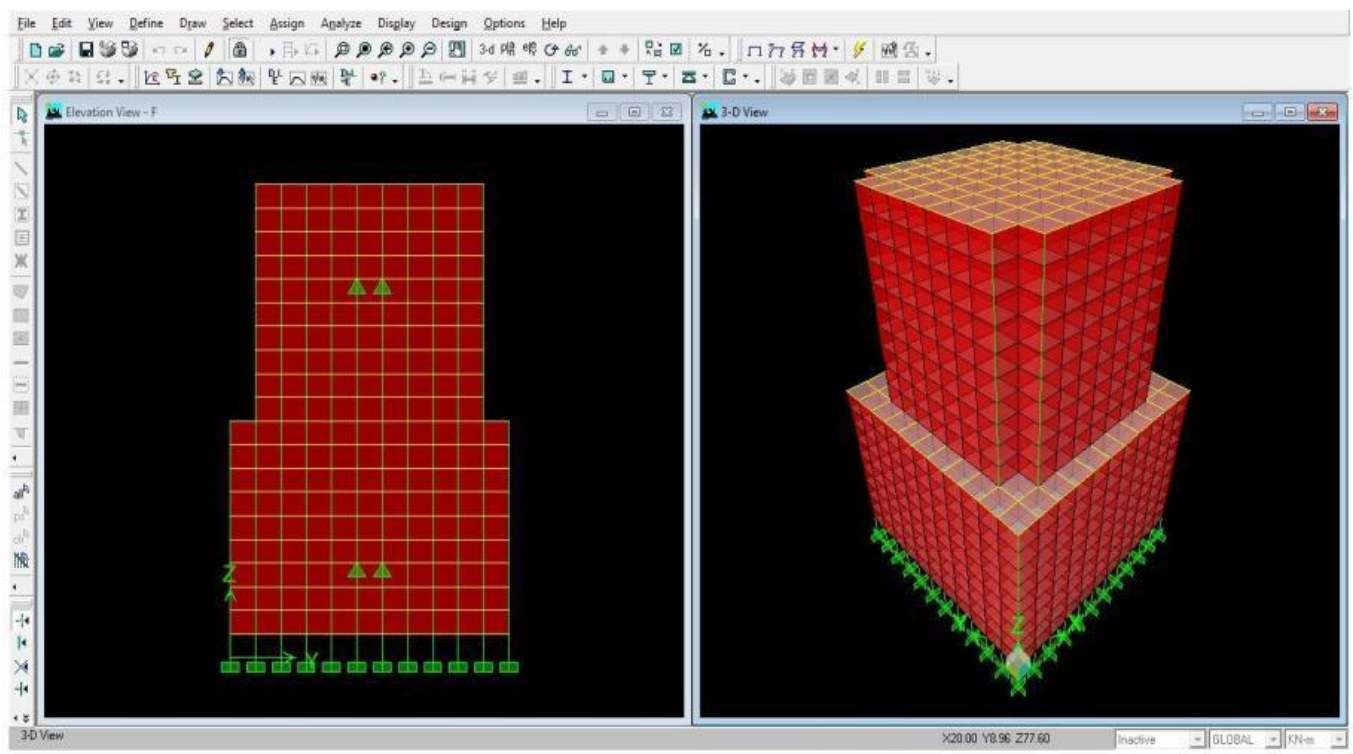

Fig 1520 storey rectangular building with two TMDs using 2-Gauss points at intermediate storey (Case 7)

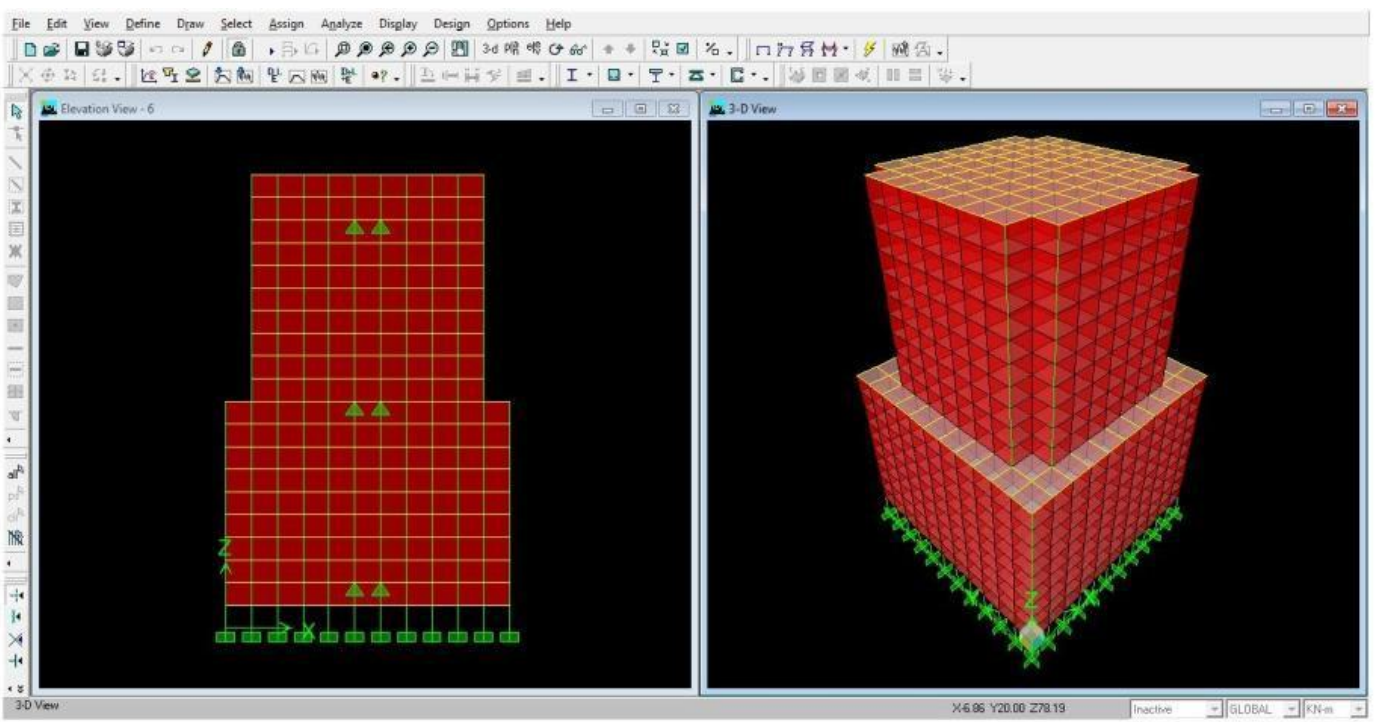

Fig 1620 storey rectangular building with three TMDs using 3-Gauss points at intermediate storey (Case 8) 


\section{RESULTS AND DISCUSSIONS}

The time period, base shear and story drift for all buildings are tabulated in Table 2, Table 3 and Table 4 respectively.

Table 2 Time period for all buildings in seconds

\begin{tabular}{|c|c|c|c|c|c|c|c|c|c|}
\hline \multirow{2}{*}{$\begin{array}{l}\text { Bui } \\
\text { ldi } \\
\text { ng }\end{array}$} & Witho & \multicolumn{2}{|c|}{ Case 1} & \multicolumn{2}{|c|}{ Case 2} & \multicolumn{2}{|c|}{ Case 3} & \multicolumn{2}{|c|}{ Case 4} \\
\hline & $\begin{array}{l}\text { Time } \\
\text { period }\end{array}$ & $\begin{array}{l}\text { Time } \\
\text { period }\end{array}$ & $\begin{array}{l}\% \text { of } \\
\text { reduct } \\
\text { ion }\end{array}$ & $\begin{array}{l}\text { Time } \\
\text { perio } \\
d\end{array}$ & $\begin{array}{l}\% \text { of } \\
\text { reduc } \\
\text { tion }\end{array}$ & $\begin{array}{l}\text { Time } \\
\text { period }\end{array}$ & $\begin{array}{l}\% \text { of } \\
\text { reduct } \\
\text { ion }\end{array}$ & $\begin{array}{l}\text { Time } \\
\text { period }\end{array}$ & $\begin{array}{l}\% \text { of } \\
\text { reduc } \\
\text { tion }\end{array}$ \\
\hline B1 & 2.873 & 1.596 & 44.46 & 1.595 & 44.46 & 1.850 & 35.59 & 2.439 & 15.08 \\
\hline B2 & 4.082 & 2.305 & 43.52 & 2.306 & 43.52 & 2.502 & 38.70 & 3.615 & 38.70 \\
\hline B3 & 5.204 & 3.040 & 41.57 & 3.040 & 41.57 & 3.271 & 37.13 & 4.787 & 8.00 \\
\hline B4 & 4.119 & 2.308 & 43.96 & 2.308 & 43.96 & 2.504 & 39.20 & 3.646 & 11.46 \\
\hline B5 & 3.179 & 1.485 & 53.27 & 1.472 & 53.69 & 1.748 & 45.02 & 2.667 & 16.11 \\
\hline B6 & 4.321 & 2.133 & 50.64 & 2.107 & 51.24 & 2.448 & 43.35 & 3.798 & 12.10 \\
\hline B7 & 6.101 & 3.112 & 48.99 & 3.075 & 49.60 & 3.202 & 47.52 & 5.557 & 8.92 \\
\hline & & \multicolumn{2}{|c|}{ Case 5} & \multicolumn{2}{|c|}{ Case 6} & \multicolumn{2}{|c|}{ Case 7} & \multicolumn{2}{|c|}{ Case 8} \\
\hline B1 & 2.873 & 0.463 & 83.86 & 0.843 & 70.63 & 0.927 & 70.63 & 0.647 & 77.46 \\
\hline B2 & 4.082 & 0.640 & 84.30 & 1.155 & 71.70 & 1.307 & 67.97 & 0.817 & 79.97 \\
\hline B3 & 5.204 & 0.777 & 85.05 & 1.611 & 69.03 & 1.702 & 67.29 & 1.226 & 76.43 \\
\hline B4 & 4.119 & 0.678 & 83.52 & 1.152 & 72.01 & 1.305 & 68.30 & 0.814 & 80.22 \\
\hline B5 & 3.179 & 0.380 & 88.03 & 0.750 & 76.41 & 0.855 & 73.09 & 0.569 & 82.08 \\
\hline B6 & 4.321 & 0.561 & 87.02 & 1.094 & 74.68 & 1.168 & 72.97 & 0.762 & 82.37 \\
\hline B7 & 6.101 & 0.688 & 88.72 & 1.541 & 74.74 & 1.668 & 72.66 & 1.146 & 81.22 \\
\hline
\end{tabular}

Table 3 Base shear for all buildings in $\mathrm{kN}$

\begin{tabular}{|c|c|c|c|c|c|c|c|}
\hline $\begin{array}{l}\text { Cases of } \\
\text { TMD } \\
\text { application } \\
\text { on } \\
\text { buildings }\end{array}$ & $\begin{array}{c}10 \\
\text { storey } \\
\text { building } \\
\mathrm{H} / \mathrm{D} \text { as } \\
0.875 \\
(\mathrm{~B} 1) \\
\end{array}$ & $\begin{array}{c}14 \\
\text { storey } \\
\text { building } \\
\mathrm{H} / \mathrm{D} \text { as } \\
1.23 \\
\text { (B2) } \\
\end{array}$ & $\begin{array}{c}20 \\
\text { storey } \\
\text { building } \\
\text { H/D as } \\
1.6(\mathrm{~B} 3)\end{array}$ & $\begin{array}{c}\text { L- } \\
\text { shaped } \\
14 \text { story } \\
\text { H/D as } \\
1.23 \\
\text { (B4) } \\
\end{array}$ & $\begin{array}{c}10 \\
\text { storey } \\
\text { building } \\
\text { H/D as } \\
3.9 \text { (B5) }\end{array}$ & $\begin{array}{c}14 \\
\text { storey } \\
\text { building } \\
\mathrm{H} / \mathrm{D} \text { as } \\
5.44 \\
(\mathrm{~B} 6) \\
\end{array}$ & $\begin{array}{c}20 \\
\text { storey } \\
\text { building } \\
\text { H/D as } \\
8 \text { (B7) }\end{array}$ \\
\hline $\begin{array}{l}\text { Structure } \\
\text { after design }\end{array}$ & 5028.87 & 5148.00 & 7314.00 & 4175.00 & 500.82 & 598.17 & 962.10 \\
\hline Case 1 & 3525.58 & 3497.00 & 5468.00 & 2758.00 & 390.08 & 450.25 & 642.90 \\
\hline$\%$ reduction & 29.89 & 32.07 & 25.24 & 33.94 & 22.11 & 24.73 & 33.18 \\
\hline Case 2 & 4158.20 & 4275.00 & 6181.00 & 3546.00 & 430.00 & 515.80 & 846.00 \\
\hline$\%$ reduction & 17.31 & 16.96 & 15.49 & 15.07 & 14.14 & 13.77 & 12.07 \\
\hline Case 3 & 951.03 & 1145.00 & 2307.00 & 663.30 & 165.89 & 219.90 & 245.00 \\
\hline \% reduction & 81.09 & 77.76 & 68.46 & 84.11 & 66.88 & 63.24 & 74.53 \\
\hline Case 4 & 1878.45 & 2156.00 & 8164.00 & 1830.00 & 268.33 & 316.64 & 786.80 \\
\hline$\%$ reduction & 62.65 & 58.12 & -11.62 & 56.17 & 46.42 & 47.07 & 18.22 \\
\hline Case 5 & 1263.57 & 1629.00 & 2598.00 & 465.90 & 316.69 & 402.86 & 731.60 \\
\hline$\%$ reduction & 74.87 & 68.36 & 64.48 & 88.84 & 36.77 & 32.65 & 23.96 \\
\hline Case 6 & 1724.48 & 1846.00 & 2850.00 & 1230.00 & 301.76 & 403.16 & 794.70 \\
\hline$\%$ reduction & 65.71 & 64.14 & 61.03 & 70.54 & 39.75 & 32.60 & 17.40 \\
\hline Case 7 & 367.16 & 590.30 & 1617.00 & 424.76 & 112.38 & 213.05 & 374.90 \\
\hline$\%$ reduction & 92.70 & 88.53 & 77.89 & 89.83 & 77.56 & 64.38 & 61.03 \\
\hline Case 8 & 655.44 & 1428.00 & 1609.07 & 753.60 & 95.01 & 137.63 & 356.00 \\
\hline$\%$ reduction & 86.97 & 72.26 & 78.00 & 81.95 & 81.03 & 76.99 & 63.00 \\
\hline
\end{tabular}

Table 4 Story drift for all buildings in $\mathrm{mm}$ 


\begin{tabular}{|c|c|c|c|c|c|c|c|}
\hline $\begin{array}{c}\text { Cases of } \\
\text { TMD } \\
\text { application } \\
\text { on } \\
\text { buildings }\end{array}$ & $\begin{array}{c}10 \\
\text { storey } \\
\text { building } \\
\text { H/D as } \\
0.875 \\
\text { (B1) } \\
\end{array}$ & $\begin{array}{c}14 \\
\text { storey } \\
\text { building } \\
\text { H/D as } \\
1.23 \\
\text { (B2) } \\
\end{array}$ & $\begin{array}{c}20 \\
\text { storey } \\
\text { building } \\
\mathrm{H} / \mathrm{D} \text { as } \\
1.6(\mathrm{~B} 3)\end{array}$ & $\begin{array}{c}\text { L- } \\
\text { shaped } \\
14 \text { story } \\
\text { H/D as } \\
1.23 \\
(\mathrm{~B} 4) \\
\end{array}$ & $\begin{array}{c}10 \\
\text { storey } \\
\text { building } \\
\mathrm{H} / \mathrm{D} \text { as } \\
3.9(\mathrm{~B} 5)\end{array}$ & $\begin{array}{c}14 \\
\text { storey } \\
\text { building } \\
\text { H/D as } \\
5.44 \\
\text { (B6) } \\
\end{array}$ & $\begin{array}{c}20 \\
\text { storey } \\
\text { building } \\
\mathrm{H} / \mathrm{D} \text { as } \\
8 \text { (B7) }\end{array}$ \\
\hline $\begin{array}{c}\text { Structure } \\
\text { after design }\end{array}$ & 52.00 & 70.00 & 100.00 & 80.00 & 40.00 & 82.00 & 160.00 \\
\hline Case 1 & 20.00 & 22.00 & 40.00 & 20.00 & 10.00 & 21.00 & 30.00 \\
\hline$\%$ reduction & 61.54 & 68.57 & 60.00 & 75.00 & 75.00 & 74.39 & 81.25 \\
\hline Case 2 & 22.00 & 23.00 & 42.00 & 20.00 & 12.00 & 24.00 & 33.00 \\
\hline$\%$ reduction & 57.69 & 67.14 & 58.00 & 75.00 & 70.00 & 70.73 & 79.38 \\
\hline Case 3 & 130.00 & 140.00 & 130.00 & 150.00 & 40.00 & 190.00 & 80.00 \\
\hline \% reduction & -150.00 & -100.00 & -30.00 & -87.50 & 0.00 & -131.71 & 50.00 \\
\hline Case 4 & 50.00 & 72.00 & 90.00 & 70.00 & 50.00 & 70.00 & 140.00 \\
\hline$\%$ reduction & 3.85 & -2.86 & 10.00 & 12.50 & -25.00 & 14.63 & 12.50 \\
\hline Case 5 & 10.00 & 10.00 & 10.00 & 10.00 & 5.00 & 10.00 & 20.00 \\
\hline$\%$ reduction & 80.77 & 85.71 & 90.00 & 87.50 & 87.50 & 87.80 & 87.50 \\
\hline Case 6 & 21.00 & 21.00 & 50.00 & 20.00 & 14.00 & 32.00 & 42.00 \\
\hline$\%$ reduction & 59.62 & 70.00 & 50.00 & 75.00 & 65.00 & 60.98 & 73.75 \\
\hline Case 7 & 20.00 & 30.00 & 20.00 & 30.00 & 11.00 & 30.00 & 40.00 \\
\hline$\%$ reduction & 61.54 & 57.14 & 80.00 & 62.50 & 72.50 & 63.41 & 75.00 \\
\hline Case 8 & 10.00 & 20.00 & 40.00 & 20.00 & 10.00 & 20.00 & 20.00 \\
\hline$\%$ reduction & 80.77 & 71.43 & 60.00 & 75.00 & 75.00 & 75.61 & 87.50 \\
\hline
\end{tabular}

\section{DISCUSSION OF RESULTS}

\subsection{Storey Rectangular Building with H/D as 0.875 (B1)}

From Table 2 it is observed that the reduction in fundamental time period of about $45 \%$ is almost the same for Cases 1 and 2, and $36 \%$ for Case 3. The reduction shrinks by $15 \%$ for Case 4 and grows on an average by $76 \%$ for the Cases 5, 6, 7 and 8. The minimum reduction is in Case 4 (around 15\%) and the maximum reduction is in Case 5 (around 84\%).

From Table 3 it is noted that the base shear of the building reduces by $30 \%$ for Case 1 and $17 \%$ for Case 2 . The reduction on an average improves by $71 \%$ for Cases $3,4,5$ and 6 and $90 \%$ for Cases 7 and 8 . The minimum reduction is in Case $2(17 \%)$ and the maximum reduction is in Case 7 $(93 \%)$.

From Table 4 it is seen that the reduction in drift of the building is around $60 \%$ for Cases 1 and 2 . But the drift increases in Case 3 by $150 \%$ and reduces in Case 4 by $4 \%$. It reduces further on an average by $71 \%$ for Cases $5,6,7$ and 8 . The minimum reduction is in Case $3(-150 \%)$ and the maximum reduction is in Case $5(81 \%)$.

\subsection{Storey Rectangular Building with H/D Ratio} as $1.23(\mathrm{~B} 2)$

From Table 2 it is observed that the reduction in fundamental time period of about $44 \%$ is almost the same for Cases 1 and 2. The reduction drops by 39\% for Cases 3 and 4 and grows on an average by $76 \%$ for the Cases 5, 6, 7 and 8 . The minimum

reduction is in Case 4 (around 39\%) and the maximum reduction is in Case 5 (around 84\%).

From Table 3 it is noted that the base shear of the building is reduced by $32 \%$ for Case 1 and $17 \%$ for Case 2 . The reduction improves by $67 \%$ for Cases 3, 4, 5 and 6 and $80 \%$ for Cases 7 and 8 . The minimum reduction is in Case 2 $(17 \%)$ and the maximum reduction is in Case $7(89 \%)$.

From Table 4 it is seen that the reduction in drift of the building is around $68 \%$ for Cases 1 and 2. But the drift increases in Case 3 by $100 \%$ and in Case 4 by 3\%. The reduction increases further on an average by $71 \%$ for Cases $5,6,7$ and 8 . The minimum reduction is in Case $3(-100 \%)$ and the maximum reduction is in Case $5(86 \%)$.

6.3 20 Storey Rectangular Building with H/D Ratio 


\section{as $1.6(\mathrm{B3})$}

From Table 2 nearly the same reduction in fundamental time period of about $42 \%$ is observed for Cases 1 and 2 . The reduction drops by $37 \%$ for Case 3 and $8 \%$ for Case 4 . But the reduction grows on an average by $74 \%$ for the Cases 5 , 6, 7 and 8. The minimum reduction is in Case 4 (around 8\%) and the maximum reduction is in Case 5 (around 85\%).

From Table 3 it is noted that the base shear of the building is reduced by $25 \%$ for Case 1 and $15 \%$ for Case 2 . The reduction rises by $68 \%$ for Case 3 , but the base shear increases by $12 \%$ for Case 4 . It reduces further on an average by $70 \%$ for Cases $5,6,7$ and 8 . The minimum reduction is in Case $2(15 \%)$ and the maximum reduction is in Case 8 (78\%).

From Table 4 it is seen that the reduction in drift of the building is around $59 \%$ for Cases 1 and 2. But the drift increases by $30 \%$ for Case 3 and decreases by $10 \%$ for Case 4. The reduction further increases on an average by $70 \%$ for Cases 5, 6, 7 and 8. The minimum reduction is in Case 3 ($30 \%$ ) and the maximum reduction is in Case $5(90 \%)$.

\subsection{4 storey L-Shaped Building with H/D Ratio as 1.23 (B4)}

From Table 2 it is observed that roughly the same is the reduction in fundamental time period for Cases 1,2 and 3 (43\%). The reduction shrinks by $11 \%$ for Case 4 and grows on an average by $76 \%$ for Cases $5,6,7$ and 8 . The minimum reduction is in Case 4 (around 11\%) and the maximum reduction is in Case 5 (around 84\%).

From Table 3 it is noted that the base shear of the building reduces by $34 \%$ for Case 1 and $15 \%$ for Case 2 . The reduction rises by $84 \%$ for Case 3 , but falls by $56 \%$ for Case 4. It reduces further on an average by $83 \%$ for Cases 5, 6, 7 and 8 . The minimum reduction is in Case $2(15 \%)$ and the maximum reduction is in Case 7 (90\%). fall

From Table 4 it is seen that the reduction in drift of the building is around $75 \%$ for Cases 1 and 2. But the drift increases by $88 \%$ for Case 3 and decreases by $13 \%$ for Case 4. The reduction further enhances on an average by $75 \%$ for Cases 5, 6, 7 and 8. The minimum reduction is in Case 3 ($88 \%$ ) and the maximum reduction is in Case $5(88 \%)$.

\subsection{Storey Rectangular Building with H/D Ratio}

\section{as 3.9 (B5)}

From Table 2 it is observed that almost the same reduction in fundamental time period of about $51 \%$ is obtained for Cases 1, 2 and 3. The reduction shrinks by $16 \%$ for Case 4 and swells on an average by $80 \%$ for Cases 5, 6, 7 and 8 . The minimum reduction is in Case 4 (around 16\%) and the maximum reduction is in Case 5 (around 88\%).

From Table 3 it is noted that the base shear of the building reduces by $22 \%$ for Case 1 and $14 \%$ for Case 2. The reduction improves by $67 \%$ for Case 3 , but shrinks on an average by $41 \%$ for Cases 4,5 and 6 . It reduces further on an average by $79 \%$ for Cases 7 and 8 . The minimum reduction is in Case $2(14 \%)$ and the maximum reduction is in Case $8(81 \%)$.

From Table 4 it is seen that the reduction in drift of the building is around $73 \%$ for Cases 1 and 2 and zero for Case 3. But the drift increases by $25 \%$ for Case 4 and reduces further on an average by $75 \%$ for Cases $5,6,7$ and 8 . The minimum reduction is in Case 3 (zero) and the maximum reduction is in Case $5(88 \%)$.

\subsection{Storey Rectangular Building with H/D Ratio}

\section{as $5.44($ B6)}

From Table 2 it is observed that the reduction in fundamental time period of about $48 \%$ is almost the same for Cases 1, 2 and 3. The reduction drops by $12 \%$ for Case 4 and grows on an average by $80 \%$ for Cases 5, 6, 7 and 8 . The minimum reduction is in Case 4 (around 12\%) and the maximum reduction is in Case 5 (around 87\%).

From Table 3 it is noted that the base shear of the building is reduced by $25 \%$ for Case 1 and $14 \%$ for Case 2 . The reduction rises by $63 \%$ for Case 3 , but descends on an average by $37 \%$ for Cases 4,5 and 6 . It reduces further on an average by $71 \%$ for Cases 7 and 8 . The minimum reduction is in Case $2(14 \%)$ and the maximum reduction is in Case 8 (77\%).

From Table 4 it is seen that the reduction in drift of the building is around $73 \%$ for Cases 1 and 2 . But the drift increases by $132 \%$ for Case 3 and reduces by $15 \%$ for Case 4. It reduces further on an average by $72 \%$ for Cases $5,6,7$ and 8 . The minimum reduction is in Case $3(-132 \%)$ and the maximum reduction is in Case $5(88 \%)$.

\subsection{Storey Rectangular Building with H/D Ratio as 8 (B7)}

From Table 2 it is observed that the reduction in fundamental time period of about $49 \%$ is almost the same for Cases 1, 2 and 3. The reduction descends by $9 \%$ for Case 4 , but grows on an average by $79 \%$ for the Cases 5, 6, 7 and 8. The minimum reduction is in Case 4 (around 9\%) and the maximum reduction is in Case 5 (around 89\%).

From Table 3 it is noted that the base shear of the building is reduced by $33 \%$ for Case 1 and $12 \%$ for Case 2 . The reduction improves by $75 \%$ for Case 3 , but shrinks on an average by $20 \%$ for Cases 4,5 and 6 . It reduces further on an average by $62 \%$ for Cases 7 and 8 . The minimum reduction is in Case $2(12 \%)$ and the maximum reduction is in Case 3 (75\%). From Table 4 it is seen that the reduction in drift of the building is around $80 \%$ for Cases 1 and 2 and $50 \%$ for Case 3 . The reduction further drops by $13 \%$ for Case 4 and rises on an average by $81 \%$ for Cases 5, 6, 7 and 8. The minimum reduction is in Case $4(13 \%)$ and the maximum reduction is in Case $5(88 \%)$. 


\section{CONCLUSION}

The elevated RCC water tank on the top of the building and intermediate storey which have hinged supports are found to be effective TMD mechanism for reduction of the three parameters viz. time period, base shear and storey drift. The usefulness of the TMD is observed when the mass ratio of TMD is in between $3 \%$ to $5 \%$ of total mass of one floor of the building. The effect of height to depth (H/D) ratio is investigated on modeling of TMD on the buildings. The methodology adopted in the present studies can be used to design a suitable TMD for each type of RCC building structures regular or irregular in plan and elevation. For buildings with one TMD modeled at the center of gravity of the top storey, and buildings with four TMDs modeled at four corners at the top storey there is no commendable reduction in all the three parameters. For buildings with one TMD modeled at the mid height maximum reduction in the base shear is achieved, but the storey drift increases conversely. And for buildings with one TMD modeled at the second storey too, there is no worthy reduction in all the three parameters. For buildings modeled with four TMDs each at quarter, half, three-quarter and full heights all the three parameters reduce simultaneously to the maximum possible extent; however, the reduction in the base shear is minor for buildings with higher H/D as against that with smaller H/D. For buildings with two TMDs modeled one at the top and other at the mid height, and buildings with two TMDs modeled using 2-Gauss points at the intermediate storey the results are comparable with the previous case. For extracting the maximum benefits, the buildings shall be modeled with three TMDs using 3-Gauss points at the intermediate storey as it reduces all the three parameters simultaneously to the maximum possible extent; and the reduction in the base shear is significant for buildings with smaller H/D as well as with higher H/D.

\section{REFERENCES}

[1] Ahsan Kareem, and Yukio Tamura (1994). "Damping systems for controlling wind induced motions of structures." Conference Proceeding, Structures Congress XII, 845-850.

[2] Alexander, A. Nicholas, and Schilder, Frank (2009). "Exploring the performance of a nonlinear tuned mass damper." Journal of Sound and Vibration, 319(1-2), 445-462.

[3] Bijan Samali, and Mohammed Al-Dawod (2003). "Performance of a five-storey benchmark model using an active tuned mass damper and a fuzzy controller." Engineering Structure, 25, 1597-1610.

[4] Bitaraf, M., Ozbulut, O. E., Hurlebaus, S., and Barroso L. R. (2010). "Application of semi-active control strategies for seismic protection of buildings with MR dampers." Engineering Structures, 32, 3040-3047.

[5] Blekherman, A. N. (1996). "Mitigation of response of high-rise structural systems by means of optimal tuned mass damper." Eastern Division, Seismic Risk Evaluation, New York, USA. Paper No. 89.

[6] Byung-Wan Jo, Ghi-Ho Tae, and Du-Wha Lee (2001). "Structural vibration of tuned mass damper-installed three-span steel box bridge." International Journal of Pressure Vessels and Piping, 78(10), 667-675.

[7] Chen, G., and Wu, J. (2001). "Optimal placement of multiple tuned mass dampers for seismic structures." Journal of Structural Engineering, 127(9), 10541062.

[8] Chi-Chang Lin, Lyan-Ywan Lu, Ging-Long Lin, and Ting-Wei Yang (2010),

[9] "Vibration control of seismic structures using semiactive friction multiple tuned mass dampers." Engineering Structures, 32(10), 3404-3417.

[10] Clark Allen, J. (1988). "Multiple passive TMDs for reducing earthquake induced building motion." Proceedings of Ninth World Conference on Earthquake Engineering, Tokyo, Kyoto, Japan, 5.

[11] Constantinou, M. C., and Symans, M. D. (1992). "Experimental and analytical investigation of seismic response of structures with supplemental fluid viscous dampers." Technical Report NCEER-92-0027, National Center for Earthquake Engineering. Research, State University of New York, Buffalo, N.Y.

[12] Den Hartog, J. P. (1947). Mechanical vibrations, Third edition, Second impression, McGraw-Hill, N.Y.

[13] Ghosh, A., and Basu, B. (2004). "Effect of soil interaction on the performance of tuned mass dampers for seismic applications." Journal of Sound and Vibration, 274(3-5), 1079-1090.

[14] Guo, Y. Q., and Chen, W. Q. (2008). "Dynamic analysis of space structures with multiple tuned mass dampers." Engineering Structures, 29(12), 3390-3403.

[15] Housner, G. W., Soon, T. T., and Masri, S. F. (1996). "Second generation of active structural control in civil engineering." Microcomputers in Civil Engineering, 11, 289-296.

[16] Kwok, K. C. S., and Samali, B. (1995). "Performance of tuned mass dampers under wind loads." Engineering Structures, 17(9), 655-667.

[17] Lee, C. L., Chen, Y. T., Chung, L. L., and Wang, Y. P. (2006). "Optimal design theories and applications of tuned mass dampers." Engineering Structures, 28(1), 43-53.

[18] Mehdi Setareh, John Ritchey, K., Thomas, M. Murray, Jeong-Hoi Koo, and Mehdi Ahmadian (2007). "Semiactive tuned mass damper for floor vibration control." Journal of Structural Engineering, 133(2), 242-250.

[19] Nawawi Chouw (2004). "Behavior of soil-structure system with tuned mass dampers during near-source earthquakes." $13^{\text {th }}$ World Conference on Earthquake Engineering, Vancouver, B.C., Canada, August 1-6, Paper No. 1353.

[20] Ormondroyd, J., and Den Hartog, J. P. (1928). "The theory of dynamic vibration absorber." Transactions, ASME, APM-50-7, 9-22.

[21] Runlin Yang, Xiyuan Zhou, and Xihui Liu (2002) . "Seismic structural control using semi-active tuned mass dampers." Earthquake Engineering and Engineering Vibration, 1(1), 111-118.

[22] Saidi, I., Gad, E.F., Wilson, J.L., and Haritos, N. (2011). "Development of a viscoelastic tuned mass damper for floor vibration applications." Engineering 
Structures, 33 (12), 3317-3328.

[23] Shimazu, T., and Araki, H. (1996). "Survey of actual effectiveness of mass damper systems installed in buildings." Eleventh World Conference on Earthquake Engineering, Paper No.809.

[24] Welt, and Modi (1989). "Experimental study on the effectiveness of TLDs under wave loading." Journal of Ocean University of Qingdao, 1(1), 80-86.

[25] Wong, K. K. F. (2008). "Seismic energy dissipation of inelastic structures with tuned mass dampers." Journal of Engineering Mechanics, ASCE, 134(2), 163-172. 